\title{
DRAFT OF GERMAN TEXT OF THE INTERNATIONAL CODE OF NOMENCLATURE OF BACTERIA*
}

\section{VORWORT}

Die beigefügte deutsche Übersetzung der im Oktober 1966 veröffentlichten englischen Fassung des "International Code of Nomenclature of Bacteria" stellt den Versuch dar, diesen Kodex in möglichst wortgetreuer Anlehnung an den englischen Originaltext dem deutschsprachigen Leser zugänglich zu machen. Zweifellos wäre es möglich gewesen, die Übersetzung in vielen Fällen flüssiger und auch eleganter zu gestalten; doch wurde bewusst darauf verzichtet, um nach Möglichkeit Missdeutungen zu vermeiden. Trotzdem sind sich die beiden Unterzeichneten darüber klar, dass es zahlreiche Verbesserungsmöglichkeiten gibt. Sie bitten-deshalb im Einverständnis mit dem Herausgebergremium des International Journal of Systematic Bacteriology um kritische Durchsicht und Verbesserungsvorschläge, damit recht bald die deutschsprachige Fassung des Code offiziell publiziert werden kann.

\section{Ralph Schulut.}

Priv. Doz Dr. Schubert

Hygiene-Institut Bonn

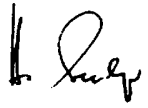

Prof. Dr. H. Seeliger

Hygiene-Institut Würzburg

* The draft copy of the revision of the English text of the International Code of Nomenclature of Bacteria, edited by the Editorial Board of the International Code, approved by the Judicial Commission, the International Committee on Nomenclature of Bacteria (ICNB), the International Association of Microbiological Societies (IAMS), and the International Congress of Microbiology, Moscow, USSR (1966), was published in the International Journal of Systematic Bacteriology (1966) 16(4):454-490. Translation of the Code into several modern languages was authorized. Professor Dr. H. Seeliger of the Hygiene Institut, Würzburg, as one of the Permanent Secretaries of the International Committee, and Privat Dozent Dr. R. Schubert, Hygiene Institut, Bonn, were asked to prepare the translation. It is here reproduced by offset. Comments or suggestions will be transmitted to $\mathrm{Dr}$. Seeliger. The sponsoring agencies are greatly indebted to Professor Dr. Seeliger and to Dr. Schubert, to the respective institutes at Würzburg and Bonn for facilities provided, and to the several bacteriologists who have collaborated. - Eds.

Reprints of this German translation of the Code are available, with covers, from the International Microbiological Fund, 221 Science Hall, Iowa State University, Ames, Iowa 50010, U.S.A. Price $\$ 1.00$. 


\section{INTERNATIONALER NOMENKLATUR - KODEX FUR BAKTERIEN.}

Der Kodex wird von der Schriftleitung. des Internationalen Komitees fur die Nomenklatur der Bakterien (I.C.N.B) herausgegeben. Die vorliegende Fassung wurde von der Schiedskommission des (I.C.N.B.), vom Internationalen Komitee für dieN.omenklatur der Bakterien (I.C.N.B.), von der Internationalen Vereinigung der mikrobiologischen Gesellschaften (I.A.M.S.) und dem IX. Internationalen Kongress fur Mikrobiologie in Moskau (UdSSR) 1966 gebilligt.

\section{KAPITEL I.}

\section{ALLGEMEINE GESICHTSPUNKTE}

Allgemeiner Gesichtspunkt 1)

Der Fortschritt der Bakteriologie kann durch ein unzweideutiges Nomenklatursystem gefordert werden, das sich in die von Botanikern, Zoologen und Virologen verwendeten Systeme zweckmåssig einfugt und das von der Mehrheit der Bakteriologen aller Nationen als verbindlich anerkannt wird. Der Internationale Kodex fur die Nomenklatur der Bakterien gilt für Bakterien und verwandte Organismen. Der botanische, der zoologische und der vorläufige virologische Kodex regeln die Nomenklatur bestimmter anderer Gruppen von Mikroorganismen wie Pilze, Algen, Protozoen und Viren.

\section{Allgemeiner Gesichtspunkt 2)}

Die Richtlinien, auf denen dieses System der Bakteriennomenklatur beruht, sind in Grundsâtze, Regeln und Empfehlungen gegliedert. Die Grundsätze (Kapitel 2) bilden die Grundlage für die Regeln und Empfehlungen.

Die Regeln (Kapitel 3) sind dazu da,

(a) den im Kapitel 2 gegebenen Grundsätzen zur Wirksamkeit zu verhelfen,

(b) die in der Vergangenheit eingefuhrte Nomenklatur in Ordnung zu bringen und

(c) fur die zukünftige Nomenklatur zu sorgen.

Die Regeln wirken im allgemeinen ruckwirkend; regelwidrige (illegitime) Namen oder Nomenklaturformen können 
nicht beibehalten werden. Gewisse Regeln geben Anhängen (Appendices) Rechtskraft und bestimmen deren Geltungsbereich. Die Nomenklaturregeln bestimmen weder die Abgrenzungen der Taxa noch deren wechselseitige Beziehungen zueinander. Sie beg renzen auch nicht die taxonomi sche Freiheit bei der Klassifizierung. I hre Hauptaufgabe liegt darin, die Richtigkeit der Namensgebung bei definierten Taxa zu gewăhrleisten.

Die Empfehlungen behandeln untergeordnete Gesichtspunkte. Sie dienen dazu, vor allem in Zukunft grössere Einheitlichkeit und Klarheit in der Nomenklatur zu schaffen. Namen und Formen, die im Gegensatz zu einer Empfehlung stehen, können nicht aus diesem Grunde verworfen werden; doch sollen die Empfehlungen verhindern, dass sich unerwünschte Vorgänge der Vergangenheit wiederholen. Empfehlungen werden den Regeln angefugt, welche dadurch ergänzt werden. Anmerkungen, die sich an Regeln oder Empfehlungen anschliessen, sollen diese erläutern oder illustrieren und haben die gleiche Kraft wie die Regeln oder Empfehlungen, denen sie zugeordnet sind.

Allgemeine Darlegungen 3)

Vorschriften (Kapitel 4) fur die Ä nderung von Regeln, fur besondere Ausnahmen von Regeln und fur ihre Interpretation in Zweifelsfällen sind durch die Einrichtung eines Internationalen Komitees fur die Nomenklatur der Bakterien der Internationalen Vereinigung der mikrobiologischen Gesellschaften und ihrer Schiedskommission. geschaffen worden.

\section{KAPITEL 2}

\section{Grundsätze.}

Grundsatz 1 .

Die Hauptaufgàben der Nomenklatur sind

(1) eine Beständigkeit der Namen anzustreben,

(2) die Verwendung von Namen zu vermeiden oder zu verwerfen, die Anlass zu Irrtumern oder Fehldeutur gen geben können oder in der Wissenschaft Verwir rung stiften. 
Von nicht minderer Bedeutung ist die vollige Vermeidung der Schaffung überflussiger Namen. Andere Überlegungen, wie grammatikalisch absolut korrekte Namensgebung, Regelmässigkeit und Wohlklang von Namen, die Beachtung mehr oder weniger vorherrschender Gebrauche, Beracksichtigung von Personen usw., sind demgegenüber-ungeachtet ihrer unbestreitbaren Bedeutung - relativ zweitrangig.

\section{Grundstaz 2.}

Wenn eine einschlägige Regel fehtt; oder wenn die sich aus der Regel ergebenden Konsequenzen mehrdeutig sind, muss der bestehende Brauch befolgt werden. Im Zweifels falle soll eine Zusammenfassung, die alle einchlägigen Gesichtspunkte beinhaltet, der Schiedskommission vorgelegt werden. damit diese ihr Gutachten (Opinion) dazu abgibt.

Grundsatz 3.

Die Nomenklatur der Bakterien und die Nomenklatur der Algen und Pilze, sowie der Protozoen und der Viren stehen insofern in einer wechselseitigen Beziehung zueinander, als der Name eines Bakterientaxons zu verwerfen ist, wenn er ein späteres Homonym eines Taxons aus dem Bereich der Algen, Pilze, Protozoen oder Viren darstellt. Die Nomenklatur der Bakterien ist unabhängig von der botanischen Nomenklatur (mit Ausnahme der Pilze und Algen) und der zoologischen Nomenklatur (ausgenommen Protozoen).

\section{Grundsatz 4.}

In der Regel werden die wissenschaftlichen Namen aller Taxa vom Lateinischen oder Griechischen abgeleitet. Wenn sie aus einer anderen Sprache als der 1 ateinischen stammen oder frei gebildet werden, mussen sie so behandelt werden, wie wenn sie aus dem Lateinischen stammen wurden.

Neuen Namen sollen möglichst lateinische Endungen gegeben werden. Die klassischen Lateinregeln für die Latinisierung griechischer und anderer Worte nicht lateinischen Ursprungs sollen befolgt werden.

\section{Grundsatz 5.}

Die Nomenklatur hat zum Gegenstand

(1) die Begriffe, die die Kategorien der Taxa bezeichnen, 
z.b. Art (Species), Gattung (Genus), Familie (Familia) und die diesbezúglichen Rangstufen dieser Kategorien.

(2) die Namen, die fur die einzelnen Taxa angewandt werden, z.B. Bacillus subtilis, Streptococcus, Spirillaceae, Spirochaetales.

Anmerkung 1 .

Das Wort Taxon (plural Taxa) entspricht dem Fachaus druck "taxonomische Gruppe" oder dem Wort "Gruppe," wo immer dieser Ausdruck in diesem Kodex sinngemäss für taxonomische Gruppe verwendet wird. Das Wort Gruppe . wird in der Bakteriologie vorzugsweise in dem Sinn gebraucht, wie in Empfehlung 8a (7) abgehandelt ist.

Anmerkung 2 .

Das Wort Name bedeutet immer, wenn nicht ausdrucklich anders angegeben, einen Namen, der gultig veröffentlicht wurde, und zwar unabhängig davon, ob er regelmâssig oder regelwidrig ist. Ein regelmässiger Name oder Beiname (Epitheton) ist ein solcher, der in Übereinstim.mung mit den Regeln steht.

Ein regelwidriger Name oder Beiname ist ein solcher, der im Widerspruch zu den Regeln steht.

Der richtige $\mathrm{N}$ ame eines Taxons mit einer besonderen Beschreibung, Stellung und Rangstufe ist derjenige Name, der nach den Regeln angenommen werden muss.

Ein Name ist wirksam veruffentlicht, wenn seine Ver offentlichung im Einklang mit Regel l1 steht.

Ein Name ist gultig veruffentlicht, wenn seine Veröffent lichung im Einklang mit den Regeln 12, 13, und 14 steht.

Grundsatz 6.

Die Regeln und Empfehlungen der bakteriologischen Nomenklatur gelten fur alle Bakterien, sowohl fur rezente als auch fur fossile, mit gewissen, besonders spezifizierten Ausnahmen.

\section{Grundsatz 7.}

Die Begriffe, die die Rangstufen der Taxa bezeichnen, werden folgendermassen definiert:

(a) Jedes Individuum wird als zu einer Anzahl von Kategorien aufeinanderfolgender Rangstufen gehorend behandelt und rangfolgemässig eingeordnet: die 
Spezies ist deren Basis. Die Hauptkategorien sind in aufsteigender Reihenfolge: Art (Species), Gattung (Genus), Familie (Familia), Ordnung (Ordo), Klasse (Classis), Division (Divisio). In einigen Gattungen kann die Zwischenstufe Untergattung (Subgenus), in manchen Familien die $\mathrm{Zwi}$ schenstufe Tribus àbgegrenzt werden.

b) Bei manchen Gattungen wird in absteigender Reihenfolge eine Unterteilung in Sektionen, Subsektionen, Serien und Unterserien anerkannt. Diese Taxa stehen zwischen Untergattung und Art.

c) Bei vielen Arten werden Unterarten und Varietäten unterschieden; in einigen Fallen werden auch infrasubspezfische Untergliederungen der Art wie Formae speciales, Serotypen, Varianten, etc. anerkannt.

d) Wenn eine grössere Zahl von Zwischenkategorien (Rangstufen) benotigt wird, werden die Bezeichnungen dieser Unterabteilungen durch das Präfix "sub" vor der jeweiligen Rangstufenbezeichnung kenntlich gemacht. So bezeichnet man mit Unterfamilie (Subfamilia) eine Rangstufe zwischen Familie und Tribus, mit Subtribus eine zwischen Tribus und Gattung etc.

e) Die Definition jeder einzelnen dieser Kategorien (Rangstufen) kann bis zu einem gewissen Grad entsprechend der personlichen Meinung und dem Stand der Wissenschaft variieren. Aber ihre relative Ordnung, durch Gebrauch sanktioniert, soll nicht geändert werden. Keine Klassifizierung kann zugelassen werden, die davon abweicht.

\section{Anmerkung:}

Eine Zusammenfassung der Namen der Kategorien derjenigen Taxa, die im bakteriologischen Kodex anerkannt werden konnen, ist nachstehend angeführt. Jene Namen, die in der Taxonomie der Bakterien als feststehend angesehen werden konnen, sind in Fettdruck mit Grossbuchstaben wiedergegeben. Diejenigen, die wahlweise verwendet werden konnen, sind doppelt unterstrichen. Die zugehorige lateinische Bezeichnung ist in Klammer angegeben.
L. Abteilung (Divisio)
2. Unterabtei Lung (Subdivisio)
3. Klasse (Classis)
4. Unterkasse (Subclas sis) 


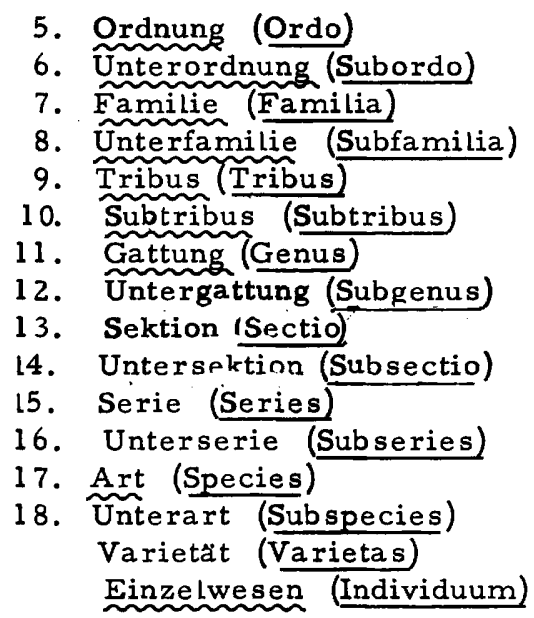

Grundsatz 8.

Der primäre Zweck der Benennung eines Taxons besteht nicht darin, die Eigenschaften oder Geschichte seines Namens anzuzeigen, sondern darin, ein Verständigungsmittel zu liefern, auf das man sich beziehen kann.

Grundsatz 9.

Jede Ordnung oder jedes Taxon von tieferem Rang, das Begrenzung, Stellung und Rangstufe besitzt, kann nux einen richtigen Namen tragen; das ist der älteste, der mit diesem Nomenklaturkodex in Einklang steht.

Vorgesehen sind Ausnahmen, deren Einfügung in die Liste der Nomina conservanda gebilligt wurde. Bei Unter gattungen, Gattungen und Taxa von hoherem Rang bis einschllesslich der Ordnung ist derjenige Name richtig, der am fruhesten veroffentlicht ist, vorausgesetzt, dass dieser im Einklang mit den Regeln dieses Kodex steht, Bei Arten ist der richtige Name die binäre und bei Unterarten die ternăre Kombination des Gattungs namens mit dem fruhesten regelgemässen Epitheton, das im gleichen Rang gultig veroffentlicht ist.

Grundsatz 10.

Die Bakteriologen sind dringend gehalten, den Namen eines 
Taxons nicht ohne schwerwiegende Grunde zu andern. Diese mussen entweder auf einem besseren Wissen tuber Fakten oder auf der Notwendigkeit beruhen, eine Nomenklatur aufzugeben, die im Widerspruch zu den Regeln dieses Kodex steht.

\title{
Grundsatz 11.
}

Die Anwendung der Namen von Taxa wird bestimmt durch den jeweiligen Nomenklaturtyp (Nom-inifer - Namensträger). Ein Nomenklaturtyp ist das konstituierende Element eines Taxons, an den der Name des Taxons permanent gebunden ist, entweder als der anerkannte Name oder als Synonym.

\section{Anmerkung.}

Die Bezeichnung "konstituierendes Element eines Taxons" einer Art oder Unterart von Bakterien entspricht dem Typexemplar (im allgemeinen ein Typ-Stamm oder eine Kultur).

\section{Grundsatz 12.}

Der Name eines Taxons hat nach den Regeln keinen Status und keinen Anspruch auf Anerkennung durch Bakteriologen, wenn er nicht gultig veroffentlicht ist.

\author{
KAPITEL 3 . \\ Nomenklatur regeln mit Empfehlungen. \\ Sektion L. \\ Benennung von Taxa verschiedener Rangstufen
}

Regel L.

Der Name jedes Taxons oberhalb der Rangstufe der Gattung ist ein Substantiv oder ein als Substantiv verwendetes Adjektiv griechischen oder lateinischen Ursprungs oder eines latinisierten Wortes im weiblichen Geschlecht oder in der Mehrzahl.

Regel 2 .

Der Name jedes Taxons oberhalb der Rangstufe der Ordnung wird bevorzugt aus einer Kombination von Merk- 
malen ausgewählt, die sich mit der Natur des Taxons so nah wie moglich decken, oder von einem einzigen Merkmal von aussergewohnlicher Bedeutung.

Regel 3.

Der Name eines Taxons zwischen Unterklasse und Gattung wird durch Anhängen des entsprechenden Suffixes zum Stamm des TypGienusnamens gebildet.

Regel 4.

Der Name jedes Taxons zwischen Unterklasse und Gattung hat ein Suffix, das den taxonomischen Rang fixiert. Das Suffix fur die Ordnung ist -ales, fur die Unterordnung -ineae, fur die Familie -aceae, fur die Unterfamilie -oideae, für den Tribus -eae, und fur den Untertribus -inae.

Regel 5a.

Der Name einer Gattung oder Untergattung ist ein Substantiv (oder ein als Substantiv verwendetes Adjektiv) im Singular mit gross geschriebenem Anfangsbuchstaben. Der Name kann beliebigen Ursprungs sein und auch auf willkurliche Weise zusammengesetzt werden. Er wird wie ein lateinisches Substantiv behandelt.

$\underline{\text { Regel 5b. }}$

Gattungs - und Untergattungs.namen sind den gleichen Regeln und Empfehlungen unterworfen und sind vom Standpunkt der Nomenklatur gleichgeordnet.

\section{Regel 5c.}

Wenn eine Gattung in Untergattungen aufgeteilt wird, muss eine der Untergattungen (und zwar die, welche die Typspezies der Gattung enthält) den gleichen Namen wie die Gattung tragen.

Anmerkung:

Autorenzitate sind der Regel 16 unterworfen. 
Regel 5d.

Wenn eine Gattung so unterteilt ist, dass sie Sektionen, Untersektionen, Serien und Unterserien enthält, müssen die Namen dieser Taxa folgendermassen gebildet werden:

(1) Der Name einer Sektion ist vorzugsweise entweder ein beschreibendes Adjektiv in der Mehrzahl-Form, das im Geschlecht mit dem Namen der Gattung ubereinstimmt, oder die Mehrzahl-Form des Namens des spezifischen Epithetons einer der im Taxon enthaltenen Arten.

(2) Der Name einer Untersektion, 'S erie oder Unterserie ist vorzugsweise die Mehrzahl des spezifischen Epithetons einer der im Taxon entha ltenen Art.

(3) Innerhalb der gleichen Gattung durfen zwei Sektionen, Untersektionen, Serien oder Unterserien nicht den gleichen Namen füren.

Anmerkung 1:

Die Namen von Sektionen, Untersektionen, Serien und Unterserien konkurrieren hinsichtlich der Prioritat oder Homonymie nicht mit den Namen von Gattungen und Unter gattungen.

Anmerkung 2:

Namen von Unterabteilungen in der Mehrzahl-Form von Adjektiven werden als Substantiva in der Mehrzahl behandelt. Sie gleichen in dieser Hinsicht den Namen der Taxa oberhalb der Gattung, die der Form nach Adjektive in der Mehrzahl sind, aber ebenso als Substantive in der Mehrzahl behandelt werden.

Empfehlung 5a.

Bakteriologen, die einen neuen Gattungs - oder Unter gattungstnamen bilden, sollen folgende Empfehlungen beachten:

(1) Keine Namen zu schaffen, die sehr lang oder sehr schwer auszusprechen sind.

(2) Namen zu bilden, die sich leicht der lateinischen Sprache anpassen lassen.

(3) Gattungen nicht Personen zu widmen, die garnicht mit der Bakteriologie oder wenigstens mit den 
Naturwissenschaften in Verbindung stehen, oder

Personen, die ziemlich unbekannt sind.

(4) Die Benutzung von Adjektiven als Substantive zu vermeiden.

(5) Namen nicht durch Kombination von Worten verschiedener Sprachen zu bilden (Nomina hybrida).

(6) Alle auf Personen zuruckgehende Gattungsnamen in der weiblichen Form zu bilden, unabhängig davon, ob sie der Erinnerung an einen Mann oder eine Frau dienen.

\section{Regel 6.}

Der Name einer Art ist eine binäre Kombination, die aus dem Namen der Gattung besteht, dem ein einziges spezifisches Epitheton folgt. Wenn ein Epitheton aus zwei oder mehreren Worten besteht, so müssen diese vereinigt oder mit einem Bindestrich versehen werden.

Anmerkung 1 .

Ein spezifisches Epitheton, das bei der ursprunglichen Veroffentlichung aus zwei oder mehréren. Worten bestand, die nicht verbunden oder durch Bindestrich versehen waren, soll nicht verworfen werden; doch sollen bei späterer Verwendung die Worte mit Bindestrich geschrieben oder verbunden werden.

Ein spezifisches Epitheton ist:

(1) ein Adjektiv, das grammatika lisch mit dem Gattungs namen ubereinstimmen muss, oder

(2) ein Substantiv im Nominativ, das hinter dem Gattungsnamen steht, oder

(3) ein Substantiv im Genetiv.

Ein spezifisches Epitheton kann jeden beliebigen Ursprungs sein und kann auch willkürlich zusammengesetzt werden. Innerhalb der gleichen Gattung dürfen zwei Artnamen nie das gleiche spezifische Epitheton tragen.

Anmerkung 2 .

Der Fachausdruck Epitheton - wie hier benutzt - besteht aus einem einzigen beschreibenden Wort oder einer einzigen beschreibenden Folge von zwei oder mehreren Worten. Wenn der Autor eines Artnamens ein Epitheton aus zwei oder mehreren Worten vorgeschlagen hat, ohne dass diese mit Binde- 
strichen verbunden oder vereinigt sind, soll vorurteilslos lediglich die Schreibweise verbessert werden.

Anmerkung 3.

Wenn die Bestandteile eines zusammengesetzten spezifischen Epithetons getrennt dekliniert werden, sind sie durch Bindestriche zu trennen. Wenn sie nicht getrennt dekliniert werden, sind sie zu vereinigen.

Empfehlung 6a.

Wenn es erwanscht ist, den Namen einer Untergattung in Verbindung mit dem Namen der Art zu bringen, kann der Name der Untergattung in Klammern zwischen den Gattungs namen und das spezifische Epitheton gesetzt werden.

Empfehlung 6b.

Bei der Bildung spezifischer Epitheta sollten sich die Bakteriologen an folgende Empfehlungen halten:

(1) ein spezifisches Epitheton zu wahlen, das im allgemeinen einen Hinweis auf das Aussehen, die Merkmale, die Herkunft, die Geschichte oder die Eigenschaften der Art darstellt. Falls von einem Personennamen abgeleitet, erinnert es gewobnlich an den Namen desjenigen, der sie entdeckte, beschrieb oder in irgend einer Weise damit befasst war.

(2) Solche Epitheta vermeiden, die sehr lang oder schwer auszusprechen sind.

(3) Solche Epitheta vermeiden, die ein Merkmal ausdrucken, das allen oder fast allen Arten der Gattung gemein ist.

(4) Die Verwendung von Namen wenig bekannter und begrenzter Örtlichkeiten vermeider, sofern das Vorkommen der Art nicht ziemlich ortlich begrenzt ist.

(5) In der gleichen Gattung Epitheta vermeiden, die sich sehr ahnlich sind, insbesondere solche, die sich nur in den letzten Buchstaben unterscheiden.

(6) Keine unveroffentlichten Namen verwenden, die sich in schriftlichen Unterlagen von Autoren finden und diesen Autoren zuschreiben, sofern letztere die Veroffentlichung nicht gebilligt haben.

(7) Zusammengesetzte spezifische Epitheta (epitheta 
hybrida) vermeiden, die Wortstämme aus zwei oder mehr Sprachen einschliessen. Dies gilt nicht fur spezifische Epitheta, die mit Bindestrichen versehen sind und bei denen die Bestandteile getrennt dekliniert werden.

\section{Empfehtung 6c:}

Es soll vermieden werden, dass der Genetiv und die adjektivische Form des gleichen spezifischen Epithetons zur Bezeichnung von zwei verschiedenen Arten der gleichen Gattung verwendet wird.

\section{Regel 7.}

Der Name einer Unterart (Varietat) ist eine ternare Kombination, die aus dem Namen der Gattung besteht, dem ein spezifisches und ein subspezifisches Epitheton folgen. Ein Epitheton einer Unterart (Varietat) wird wie das einer Art gebildet. Wenn es die Form eines Adjektivs hat und nicht wie ein Substantiv gebraucht wird, stimmt es im Geschlecht mit dem des Gattungs.namens uberein.

Weder innerhalb der gleichen Art noch innerhalb der gleichen Gattung durfen zwei Unterarten das gleiche subspezifische Epitheton tragen.

Wenn eine Art in Unterarten unterteilt wird, muss das subspezifische Epitheton der Unterart, die den Typus der Art enthălt, das gleiche sein wiè das der Art.

\section{Regel 8.}

Namen von infrasubspezifischen Unterabteilungen (infrasubspezifische Formen). Eine infrasubspezifische Unterabteilung ist ein Taxon von niedrigerem Rang als die Unterart. Eine infrasubspezifische Form ist eine der gleichgeordneten Bezeichnungen innerhalb eines infrasubspezifischen Taxons. Die Namensgebung fur Taxa vom Rang der Unterart aufwärts ist durch die Anwendung der Regeln und Vorschriften des Kodex bestimmt. Die Namen der verschiedenen Taxa, die als infrasubspezifische Form anerkannt werden, sind den allgemeinen Regeln und Empfehlungen dieses Kodex nicht unterworfen, sondern Lediglich Gegenstand folgender Empfehlungen: Als Fachausdrucke (Termini) zur Bezeichnung infrasubspezi fischer Unterteilungen sind allgemein anerkannt: 
Stamm, Isolat, Forma specialis, Biotyp, Serotyp, Morphotyp, Phagotyp, Lysotyp, Phase, Gruppe. Weniger allgemein verwendet werden die Fachausdrucke (Termini): Stadium, Zustand, Chemovar, Chemotyp, Cultivar.

Eine infrasubspezifische Form innerhalb einer Art wird durch den Namen der Art bezeichnet, dem der Fachausdruck folgt, der die infrasubspezifische Unterabteilung angibt (wie Serotyp); diese wird ihrerseits durch eine infrasubspezifische Be zeichnung oder bzw. ein entsprechendes Epitheton bezeichnet. Das kann ein lateinisches oder ein latinisiertes Wort sein, ein Trivialname oder ein Wort, eine Zahl, ein Buchstabe oder eine Formel, mit der Absicht, die Form zu charakterisieren.

Das vollstandige Zitat eines Namens einer infrasubspezifischen Form enthălt die binäre Kombination des Artnamens, gefolgt vom Fachausdruck, der die infrasubspezifische Unterabteilung bezeichnet, dieser ist wiederum gefolgt vom Epitheton der infrasubspezifischen Form (oder dem Ersatz dafur).

Ein lateinischer oder latinisierter infrasubspezifischer Name kann von einem spateren Prufer in den Rang einer Unterart oder Art angehoben werden. Wenn der Name so angegeben wird, gilt hinsichtlich der Priorität fur seine Einordnung in den neuen Rang das Datum der Anhebung, und der Name wird dem Autor zugeschrieben, durch den die Anhebung vorgenommen wurde.

Von wichtigen infrasubspezifischen Formen sollen Referenz-Stämme (-Kulturen) bestimmt werden.

Die Bezeichnungen oder Epitheta, die zur Benennung infrasubspezifischer Formen dienen, sind untereinander in jeder Unterabteilung gleichgeordnet, aber nicht gleichgeordnet den Namen von Spezies oder Subspezies.

Empfehlung 8a.

Autoren von Namen infrasubspezifischer Untereinheiten von Bakterienarten sollten sich an folgende Empfehlungen und Definitionen halten:

(1) Ein Stamm leitet sich von den Nachkommen eines einzigen Isolats in Reinkultur ab. Er kann auf jede beliebige Weise bezeichnet werden, so z.B. durch den Namen des fur seine Isolierung Verantwortlichen (wie Corynebacterium diphtheriae Stamm ParkWilliams), durch den Namen einer Ortlichkeit, durch eine $\mathrm{Zahl}$ oder ein ahnliches im Laboratorium ubliches Unterscheidungszeichen. 
Mit "Stamm" konnen auch Bakterienkulturen bezeichnet werden, die den gezuchteten "Varietaten" (Cultivar) hoherer Pflanzen entsprechen und denen eine besondere wirtschaftliche Bedeutung zukommt.

(2) Ein Spezialform (forma specialis) ist eine infrasubspezifische Form, die einer infrasubspezifischen Unterabteilung einer Art eines parasitären, symbiontischen oder komensalen Mikroorganismus angehort und die sich primär durch Adaptation an einen bestimmten Wirt oder Standort auszeichnet. Sie wird vor.zugsweise mit dem wissenschaftlichen Namen des Wirts im Genetiv benannt.

(3) Typus ist eine Bezeichnung, die hăufig in fehlerhafter Weise zur Bezeichnung von Unterabteilungen einer Art verwendet worden ist, und zwar besonders in Fallen, bei denen die Unterscheidung.smerkmale zur Rechtfertigung der Anerkennung einer Unterart als nicht ausreichend angesehen wurden. Die Bezeich nung "Typus" sollte in der Bakteriologie (wie in der gesamten Biologie) strikt in dem Sinn verwendet werden, wie er in Grundsatz 11 und Regel 9 definiert ist. Sie sollte nicht dazu benutzt werden, infrasubspezifische Formen auf der Basis von Antigeneigenschaf ten zu bezeichnen. Es wird empfohlen, wo immer sinnvoll, die folgenden Fächausdrucke für die Bezeichnung infrasubspezifischer Untereinheiten einer Art zu verwenden:

Forma specialis Biotyp, Serotyp, Morphotyp, Lysotyp (Phagtyp), Weniger allgemein sind die Fachausdracke: Stadium, Zustand, Chemovar, Chemotyp und Cultivar. Es wird empfohlen, den Fachausdruck Serotyp (oder serologischen Typus) fuin infrasubspezifische Formen zu benutzen, die auf antigenen Eigenschaften beruhen. Es wird empfohlen, den Fachausidruck Biotyp (oder fhysiologischer Typus) fur infrasubspezifische Formen zu verwenden, die auf Unterschieden in physiologis chen oder biochemischen Eigenschaften beruhen. Es wird empfohlen, die Bezeichnung Morphotyp (oder morphologischer Typus) fur infrasubspezif ische Formen zu benutzen, die auf bemerkenswerten Unterschieden in morphologischen Eigenschaften beruhen. Es wird empfohlen, die Bezeichnung Lysotyp (Phagotyp oder Phagentypus) für infrasubspezifische Formen zu verwenden, die auf dem 
Verhalten gegenuber Phagen beruhen.

4) Die Bezeichnung "Phase" sollte auf gut umrissene Stadien von natülich vorkommenden, alternierenden Variationen beschränkt werden.

5) Zustand (oder Stadium) ist die Bezeichnung, die man den rauhen, glatten, mukbsen und ähnlichen Varianten gibt, die in Kulturen vieler Bakterienarten auf treten. Diese werden ublicherweise als alternierende Zustände betrachtet, die oft reversibel sind, von einigen Autoren sogar als Teil eines pleomorphen Lebenszyklus angesehen werden. Sie konnen mit einem deskriptiven Trivialnamen bezeichnet werden.

6) Der Fachausdruck "Chemovar" (Chemotyp) kann zur Bezeichnung infrasubspezifischer Unterabteilungen zwecks Erfassung von infrasubspezifischen Formen oder Stămmen verwendet werden, die durch die Bildung einer chemischen Substanz charakterisiert sind, die normalerweise vom Typstamm der Art nicht oder in unterschiedlicher Menge gebildet wird.

7) Der Fachausdruck "Gruppe" ist in der Bakteriologie mit grosser Sorgfalt zu verwenden und muss wohl definiert sein, damit Mehrdeutigkeiten vermieden werden. Er ist in den verschiedensten Bereichen der Bakteriologie allerdings in einem manchmal recht unterschiedlichen Sinn verwendet worden. "Gruppe" kann als passende Bezeichnung fur eine Sammlung von Organismen mit gemeinsamen Eigen-. schaften benutzt werden. In vielen Fällen gründen sich die "Gruppen" auf Antigenanalyse. Die Gruppen sind dann Ansammlungen verwandter Serotypen. Der Fachausdruck "Gruppe" ist in einigen Fällen gebraucht worder, um die Benutzung richtiger Nomenklaturnamen von Taxa, wie Gattung oder Art, zu umgehen. Solcher Gebrauch fuhrt zu Verwirrung und sollte vermieden werden.

\section{Sektion 2.}

Bezeichnung von Nomenklaturtypen

Regel 9a.

Für jedes Taxon, das dieser Regel unterworfen ist, soil ein Typ bezeichnet werden. Dieser Nomenklaturtup (nominifer-Namensträger) ist das konstituierende Element des Taxons, mit dem der Name des Taxons dauernd verknüpft 
ist. Der Typ einer Art oder Unterart ist vorzugsweise ein bestimmter Typ-Stamm oder in besonderen Fallen eine Beschreibung, ein konserviertes Exemplar, ein Pra jarat oder eine Abbildung. Depr Typ einer Gattung ist eine ihm zugehorige Art, die in Ubereinstimmung mit Regel 9c bezeichnet ist. Der Typ einer Ordnung oder Unterordnung, einer Familie oder Unterfamilie, eines Tribus oder Subtribus ist die Gattung, auf deren Bezeichnung der Name des hoheren Taxons begründet ist. Der Typ eines Taxons oberhalb einer Ordnung ist eine in ihm enthaltene Ordnung. Der Typ eines Taxons soll vom Autor zum Zeitpunkt seines Vorschlages festgelegt werden.

Empfehlung 9a.

Eine Sektion kann vom Autor benannt werden:

(1) indem ein beschreibendes Adjektiv vorgeschlagen wird: In diesem Falle soll der Autor die Leitspezies (Typspezies) bezeichnen.

(2) indem die Mehrzahl-Form des spezifischen. Epithetons einer der erfassten Arten vorgeschlagen wird, die dadurch als Typspezies festgelegt wird. Eine Untersektion, eine Serie oder eine Unterserie kann von einem Autor durch Vorschlag der Mehrzahl-Form eines spezifischen Epithetons einer in ihr enthaltenen Spezies benannt werden. Diese wird dadurch zur Typspezies.

\section{Regel 9b.}

Bestimmung des Nomenklaturtyps eines Taxons im Rang oberhalb einer Gattung.

Der Nomenklaturtyp einer Ordnung, Unterordnung, Familie, Unterfamilie, bzw. eines Tribus oder Subtribus, dessen Name in Übereinstimmung mit den Regeln gebildet wurde, ist diejenige Gattung, von deren Bezeichnung der Name des hoheren Taxons, abgeleitet worden ist. Das Nomenklatur typgenus einer Familie, deren Name zwar konserviert, aber nicht in Übereinstimmung mit Regel 3 gebildet wurde, soll von der Schiedskommission festgelegt werden. Der Nomenklaturtyp eines Taxons im Rang oberhalb einer Ordnung darf vom Autor zum Zeitpunkt seines Vorschlages festgelegt werden. Wenn nicht, kann er von der Schiedskommission bestimmt werden. 


\section{Anmerkung:}

Wenn Unterabteilungen von Familien (Unterfamilie, Tribus, Subtribus) anerkannt werden, muss ein Taxon jede Kategorie des Typgenus der Familie enthalten; seine Bezeichnung sollte vom Namen des Typgenus hergeleitet sein.

Regel 9c.

Bestimmung des Nomenklaturtyps einer Gattung oder Untergattung.

(1) Der Nomenklaturtyp (Typspezies) einer Gattung oder Untergattung ist der Name der einzigen Art oder einer der Arten, die in der betreffenden Gattung oder Untergattung bereits bei der urspranglichen gultigen Veroffentlichung eingeschlossen war.

\section{Anmerkung:}

Der Ausdruck "Typspezies" soll der Bezeichnung "Genotyp $\mathrm{p}^{*}$ oder jeder anderen Bezeichnung vorgezogen werden, die sich auf die Typspezies einer Gattung bezieht.

(2) Wenn der Autor in der Original-Veröffentlichung eines Gattungs-oder untergattungsnamens eindeutig eine Typspezies ausgewăhlt hat, soll diese Art als Nomenklaturtyp (Typspezies) angenommen werden und zwar ungeachtet anderer Überlegungen (Typenwahl durch Original-Bezeichnung).

\section{Anmerkung:}

Die Bedeutung des obigen Ausdrucks "eine Typspezies ausgewăhlt hat" soll in strengem Sinne ausgelegt werden.

Das Erwähnen einer Art als Illustration oder Beispiel fur eine Gattung stellt keine Typwahl dar.

(3) Wenn der Autor eines Gattungs - oder Untergattungs namens in seiner Original-Veroffentlichung keine Typspezies benannt hat; kann der Typ durch einen folgenden Autor aus gewählt werden. Dem Autor, der als erster seine Wahl trifft, muss gefolgt werden, wenn nicht zu beweisen ist, dass seine Wahl nicht in Übereinstimmung mit einer der folgenden Regeln steht:

a) Wenn die Gattung bei der Original-Veroffentlichung nur aus einer Art bestand, soll diese Art der Nomen- 
klaturtyp sein (Typspezies) (Wahl durch Monotypie).

b) Wenn die Gattung bei der Original-Verßffentlichung mehr als eine Art enthielt, soll eine dieser Arten als Typspezies ausgewählt werden. Jedoch sollen Species inquirendae, Arten, die nur unsicher als zur Gattung gehorig angesehen werden, Arten, die in irgen deiner Weise aussergewbhnlich sind, Arten die eindeutig der Beschreibung der Gattung wider sprechen (vorausgesetzt, dass andereihr entsprechen), und Arten, die Eigenschaften besitzen, von denen feststeht, dass sie entsprechend der Beschreibung der Gattung selten oder ungewohnlich sind, bei der Wahl des Typs ausgeschlossen werden.

c) Wenn keine der Arten, die von ei nem Autor in seiner Original-Beschreibung und -Veroffentlichung eines Gattungsnamens aufgefuhrt sind, anerkannt werden kann - d.h., wenn keine identifizierbare Typspezies in tbereinstimmung mit den Regeln aus gewahlt werden kann - kann die Schiedskommission dazu eine Meinungsãusserung abgeben, in der festgestellt wird, dass solch ein Gattungsname als nomen rejiciendum anzusehen ist und keinen Status in der Nomenklatur hat. Wenn jedoch ein solcher Gat tungsname zur Benennung identifizierbarer Arten spater ublich geworden ist, kann eine der letztgenannten Arten durch internationale Vereinbarung als Typspezies ausgewahlt und der Gattungsname dem Autor des Binominals zugeschrieben werden, das als Typspezies bezeichnet wird. Solche Wahl einer Typspezies und Anerkennung des Autors eines Gattungsnamens muss auf einer Meinungsäusserung der Schiedskommission beruhen; wenn diese angezweifelt wird, muss ihre Gultigkeit durch Massnahmen des Internationalen Komitees fur die Nomenklatur der Bakterien bestimmt werden.

d) Die Veroffentlichung eines neuen Gattungsnamens als anerkannten Ersatz fur einen fruheren andert den Typ der Gattung nicht.

\section{Regel 9d.}

(1) Der Typ einer Art oder Unterart ist vorzugsweise ein lebender Stamm, der in einem bakteriologischen Laboratorium oder besser in einer der permanent eingerichteten Kulturensammlungen gehalten wird, von wo er fur Studienzwecke erhaltlich ist. 


\section{Anmerkung I:}

Bei einer Art, die nicht in Laboratoriumskulturen gehalten werden kann oder von der weder Typstamme noch Neotypstämme besiehen, gilt als Typ die Originalschreibung, ein Original-Präparat oder eine OriginalAbbildung.

\section{Anmerkung 2: Definitionen:}

a) Der Fachausdruck Kultur soll in dem Sinn interpretiert werden, dass jede Methode der Erhaltung von Organismen im lebenden Zustand gemeint ist (in einem Nährboden, in einem Wirt durch Passage, in Zellen oder Exsudaten, eingefroren oder in getrocknetem Zustand).

b) Ein Typstamm ist jede Lebende Kultur eines Mikroorganismus, die einen Abkummliag der Originalkultur oder ein Isolat darstellt, wonach der Autor, der den Organismus erstmalig beschrieben hat, seine Original-Beschreibung anfertigte und die ferner als Reinkultur aufbewahrt worden ist und in ihren Eigenschaften mit der Original-Beschreibung ubereinstimmt.

c) Ein Neotypstamm ist ein Stamm, der durch internationale Übereinkunft als Ersatz fịr einen nicht mehr existierenden Typstamm angenommen wurde. Er muss mit Bestimmungsmerkmalen ubereinstimmen die vom ursprünglichen Beschreiber mitgeteilt wurden. Ein Neotypstamm muss durch einen Autor im International Journal of Systematic Bacteriology vorgeschlagen werden und zwar zusammen mit einem vollen Zitat, einer Beschreibung oder mit einem Hinweis auf eine gultig veroffentlichte Beschreibung, sowie der Angabe einer ständigen Kulturensammlung, wo der Stamm hinterlegt ist. Der Neotypstamm gilt mit dem Datum der Veroffentlichung in dieser Zeitschrift als festgelegt. Alle Einsprüche dagegen sollten an die Schiedskommission gerichtet werden.

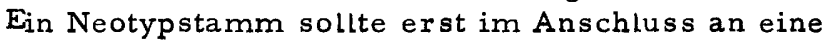
sorgfăltige Suche nach der Originalkultur vorgeschlagen werden. Wenn die Originalkultur späterhin wiederentdeckt wird, soll die Angelengenheit sofort vor die Schiedskommission gebracht werden. 
d) Ein Referenzstamm ist weder ein Typstamm noch ein Neotypstamm, sondern eine Kultur (Stamm), die von einem Autor als Standard in einer Untersue chung über eine verwandte Gruppe von Keimen verwendet wird. Ein Referenzstamm hat keinen Nomenklatur status.

\section{$\underline{\text { Regel 9d(2) }}$}

Wenn der Autor in der Original-Veroffentlichung eines Art- oder Unterartnamens eindeutig einen Typstamm festgelegt oder wenn er nur einen einzigen Stamm beschrieben hat, soll dieser Stamm ungeachtet anderer Überlegungen (ursprüngliche Bezeichnung) als Typstamm angenommen werden.

\section{Anmerkung:}

Der Ausdruck "eindeutig einen Typstamm festgelegt" soll in strengem Sinne ausgelegt werden.

Regel 9d(3)

Wenn der Autor in der Original-Ver bffentlichung des Namens einer Art oder Unterart keinen Typstamm festgelegt hat, kann von einem späteren Autor ein Typstamm bezeichnet werden. Dem Autor muss gefolgt werden, der als erster seine Wahl trifft.

\section{Empfehlung 9b.}

Wenn Autoren den Namen eines neuen Taxons veroffent lichen, sollten sie den Nomenklaturtyp des benannten Taxons sorgfältig bezeichnen. Dieser Typ bestimmt die Anwendung des Namens fur den Fall, dass dieses Taxon später unterteilt wird.

\section{Empfehlung 9c.}

Grosstes Gewicht ist auf die Bewahrung des ursprung lichen Typenmaterials zu legen, auf das sich die Beschreibung einer neuen Spezies und Subspezies grundet. Wenn der Mikroorganismus in Reinkultur aufbewahrt werden kann, sollte eine authentische Kultur als Typkultur bezeichnet und in einer oder mehreren der stăndigen Kulturensammlungen hinterlegt werden. 
Eingedenk der morphologischen, biochemischen, antigenetischen und die Virulenz betreffenden Veränderungen, die als Ergebnis wiederholter Subkultur auftreten konnen, sollte jede Vorsorge getroffen werden, solche Kulturen so zu halten, dass sie sich moglichst wenig verändern. Es ist ebenso wichtig, dass Beschreibungen, Abbildungen und Diagnosen neuer Arten und Unterarten so vollständig wie moglich sind.

\section{Sektion 3}

Die Veroffentlichung von Namen.

Regel 10.

Der L. Mai 1753, das Datum der Veroffentlichung der ersten Auflage von Linné's Species Plantarum, gilt als Anfangs.datum fur die gultige Veroffentlichung von Bakterien.

Regel 11.

Eine Veroffentlichung wird nach diesem Kodex durch den Verkauf oder die Verte ilung von Druckschriften an die Offentlichkeit oder an bakteriologische Institutionen wirksam. Keine andere Form der Veroffentlichung wird als wirksam anerkannt (wirksame Veroffentlichung). Die Mitteilung neuer Namen auf einer offentlichen Versammlung oder wissenschaftlichen Konferenz stellt keine wirksame Publika tion dar. Die Einbeziehung eines Namens eines Bakterientaxons in einem veroffentlichten Patentantrag oder genehmigten Patent stellt keine wirksame Veroffentlichung dar. Wenn Sonderdrucke oder Separata von Zeitschriften oder anderen Arbeiten verkauft oder im voraus abge ben werden, gilt das Datum auf dem Separatum als Datum der wirksamen Veroffentlichung, es sei denn, dass das Datum offensichtlich falsch ist. Das Datum der Annahme eines Artikels auf Veroffentlichung, das in der Veroffentlichung ange geben ist, zeigt nicht das Datum der wirksamen Veroffent lichung an und hat keine Bedeutung fur die Feststellung der Prioritât bei der Veroffentlichung von Namen.

Regel 12a.

Der Name eines Taxons ist nicht galtig veruffentlicht, 
sofern er nicht- (1) wirksam veroffentlicht (s. Regel 11) und (2) mit einer Beschreibung des Taxons oder mit einem Literaturhinweis auf eine fruher wirksam veroffentlichte Beschreibung versehen ist.

Der Name eines Bakterientaxons, der in einem Patentantrag oder einer Patentzulassung nicht wirksam veroffent licht ist, kann durch eine mit Regel 11 in Einklang stehende spätere Veroffentlichung eines Namens gultig publiziert werden, vorausgesetzt, dass solch einer Veroffentlichung eine Beschreibung des Taxons oder ein Literaturhinweis auf eine fruhere wirksam veroffentlichte Beschreibung beigefugt ist. Das Datum der Zulassung des Patents soll angegeben werden, und dieses wird dann als Datum der Veroffentlichung anerkannt.

\section{Anmerkung:}

Die Worte "guttig" und "gultig veroffentlicht" bedeuten, so, wie sie im Kodex verwendet werden, "mit Status in der Nomenklatur" und die Worte "ungultig" oder "ungultig veroffentlicht" bedeuten "ohne Status in der Nomenklatur".

\section{Regel 12b.}

Eine gultige Veroffentlichung wird nicht dadurch erreicht, dass eine Kultur oder ein Präparat von Bakterien in einer Sammlung oder Ausstellung, die der Öffentlichkeit zugănglich sind, lediglich mit einem Namen versehen werden.

\section{Regel 12c.}

Ein Name, der

(1) vom Autor, der ihn veroffentlicht hat, nicht anerkannt wird, oder

(2) der lediglich in Erwartung der küntigen Annahme oder einer besonderen Abgrenzung, Stellung oder Rangstufe des betreffenden Taxons vorgeschlagen wird, oder

(3) ein Name, der lediglich zufallig erwahnt wird, ist nicht gultig publiziert.

Anmerkung:

Absatz (1) oben bezieht sich nicht auf Namen oder Epitheta, die zwar mit einem Fragezeichen oder einem anderen Hinweis fur taxonomische Zweifel versehen, aber ver fffentlicht und vom Autor anerkannt wurden. Mit 
"zufälliger Erwähnung" eines neuen Namens oder einer Kombination ist die Erwähnung durch einen Autor gemeint, der nicht klar herausstellt, dass er einen neuen Namen oder eine neue Kombination vorschlägt.

$\underline{\text { Regel 12d. }}$

Der Name eines Taxons ist nicht gultig veroffentlicht, wenn er lediglich als Synonym zitiert ist.

$\underline{\text { Regel } 12 \mathrm{e} .}$

Der Name eines Taxons ist nicht durch die blosse Erwähnung der eingeschlossenen untergeordneten Taxa veroffentlicht.

$\underline{\text { Regel } 12 f .}$

Das Datum eines Namens oder eines Epithetons ist das seiner galtigen Veroffentlichung. Fur Zwecke der Prioritat werden jedoch nur gultige Namen und Epitheta, die in gulti gen Kombinationen veroffentlicht wurden, in Betracht gezogen. Wenn das Gegenteil nicht bewiesen werden kann, muss das Datum der Arbeit, die den Namen oder das Epitheton enthält, als richtig angesehen werden.

Anmerkung:

Die Fassung "Epitheta, die in Legitimer Kombination veroffentlicht wurden" ist unter Beachtung der Bestimmungen in Regel $14 \mathrm{zu}$ interpretieren.

Empfehlung 12a.

Wenn Namen von neuen Taxa in einer, der Mehrheit der Bakteriologen nicht vertrauten Sprache veroffentlicht werden, wird empfohlen, dass die Autoren gleichzeitig die Bestimmungsmerkmale in einer mehr gebräuchlichen Sprache veroffentlichen.

\section{Empfehlung 12b.}

Autoran sollten des Er scheinungsdatum ihrer Arbeiten genau angeben. Im Falle, dass eine Arbeit in Teilen erscheint, sollen auf der letzten veröffentlichten Seite des 
Bandes die genauen Erscheinungsdaten angegeben werden, an denen die verschiedenen Hefte oder Teile des betreffenden Bandes veroffentlicht wurden, desgleichen die Seitenzahlen in jedem Band.

Empfehtung 12c.

Wenn Arbeiten in Zeitschriften erscheinen, sollte der Autor vom Verleger verlangen, dass auf den Separata bzw. Sonderdrucken das Erscheinungsdatum der Veroffentlichung (Jahr und Monat moglichst auch der Tag) sowie der Name der Zeitschrift angegeben wird, aus der die Arbeit entnommen wurde. Separata oder Sonderdrucke sollten immer die Paginierung der Zeitschrift tragen, deren Teil sie sind; falls erwunscht ist, konnen sie auch zusätzlich mit eigenen Seitenzahlen versehen werden.

\section{Empfehlung 12d.}

Ein Autor, der ein neues Taxon beschreibt und benennt, soll den Rang des betreffenden Taxons sowie den Namen und Rang des nächst hơheren Taxons angeben (z.B. den Namen einer Familie, der eine neue Gattung zugeordnet wird, den Namen einer Ordnung, in der eine neue Familie untergebracht wird).

\section{Empfehlung 12e.}

Wenn ein Autor einen neuen Gattungs - oder Untergattungs namen veröffentlicht, soll er dessen Etymologie angeben. Gleiches gilt für ein neues Epitheton, wenn dessen Bedeutung nicht offensichtlich ist.

\section{Regel 13.}

Der Name einer Gattung oder Untergattung ist nicht gultig veroffentlicht

a) wenn ihm nicht beigefügt ist

1) eine Beschreibung der Gattung oder

2) das Zitat einer vorher wirksam veroffentlichten Beschreibung der Gattung als eine Untergattung (oder der Untergattung als eine Gattung) oder

3) - im Falle einer monotypischen neuen Gattung. auf der Basis einer neuen Art - eine lombi- 
nierte Gattungs - und Artbeschreibung der einzigen, zu dieser Gattung gehorenden Art.

b) Wenn die Beschreibung der gattung auf Untersuchungen an unreinen oder Mischkulturen beruht - d.h., wenn offenkundig ist, dass sich die Beschreibung auf die Eigenschaften von mehr als einer Art in Mischkultur grundet. Diese Feststellung bezieht sich nicht auf den Namen einer Gattung oder Untergat tung, deren Beschreibung auf morphologische oder andere Merkmale und nicht auf Wachstum in Reinkultur zurückgeht.

\section{Anmerkung:}

Eine Beschreibung einer neuen Art, die einer neuen monotypschen Gattung zugeordnet ist, wird ebenfalls als eine Gattungsbeschreibung behandelt, wenn die Gattung nicht beschrieben wird. In ahnlicher Weise wird die Beschreibung einer monotypischen Gattung, die auf einer neuen Art beruht, als Art-Beschreibung behandelt, sofern der Gattungsname und das spezifische Epitheton gemeinsam veröffentlicht werden und die Art nicht getrennt beschrieben wird.

Empfehlung 13a.

Eine kombinierte Gattungs - und Art-Beschreibung sollte die Punkte erwähnen, durch die sich die neue Gattung von verwandten Gattungen unter scheidet.

Regel 14a.

Der Name einer Art ist nur dann gülig veroffentlicht, wenn seine Veroffentlichung mit den folgenden Erfordernissen im Einklang steht:

1) Er muss als binäre Kombination veroffentlicht werden, die aus einem Gattungsnamen besteht und von einem einzigen spezifischen Epitheton gefolgt wird.

2) Ihm muss eine Beschreibung der Art oder das Zitat einer vorher wirksam veroffentlichten Beschreibung beigefugt sein.

3) Die Beschreibung darf nicht auf den Eigenschaften von mehr als einer Art in Misch-oder unreinen Kulturen beruhen, Diese Feststellung bezieht sich nicht auf den Namen einer Art, deren Beschreibung auf der Morphologie oder anderen Merkmalen und nicht auf Wachstum in Kulturen beruht. 
$\underline{\text { Regel 14b. }}$

Der Name einer Unterart (Varietat) ist nur dann gultig veroffentlicht, wenn seine Veroffentlichung mit den folgenden Erfordernissen im Einklang steht:

l) Er muss als ternäre Kombination veroffentlicht werden, die aus einem Gattungsnamen besteht, ge folgt. von einem einzigen spezifischen Epitheton und dieses wiederum von einem einzigen subspezifischen Epitheton.

2) Ihm muss eine Beschreibung der Unterart oder das Zitat einer vorher und wirksam veroffentlichten Beschreibung beigefugt sein.

3) Der Autor muss klar feststellen oder darauf hinweisen, dass eine Unterart benannt wird.

\section{Sektion 4.}

Zitieren von Autoren und Namen.

Regel 15a.

Damit der Hinweis auf den Namen eines Taxons (unitar, binär oder ternär) genau und vollständig ist und damit der Zeitpunkt schnell verifiziert werden kann, ist es notig, den Autor oder die Autoren zu zitieren, die den betreffenden Namen zuerst gultig veroffentlicht haben.

Anmerkung:

Wo offensichtlich mehrere Autoren den Artikel, in dem der Name eines neuen Taxons veroffentlicht wird, verfasst haben und keine definitive Bezeichnung einer einzigen Person als Autorenname erfolgt ist, darf das Zitat so erfolgen, dass entweder die Namen aller Autoren oder der Name des ersten Autors, gefolgt von der Abkürzung "et al." (et alii), angegeben wird.

$\underline{\text { Regel 15b. }}$

Ein bewahrter Name, dessen ursprunglicher Typ aus geschlossen wurde, darf nicht dem urspranglichen Autor mit solchen Ausdrucken wie emend., mutatis charact., etc. zugeschrieben werden; vielmehr ist der Autor, dessen Auffassung als bleibend bewahrt (konserviert) wird, als Urheber (authority) zu zitieren. 


\section{Anmerkung:}

Die Beibehaltung eines Namens in einem den Typ ausschliessenden Sinn kann nur auf dem Wege der Namensbewahrung (Konservierung) erfolgen.

\section{Anmerkung:}

Siehe Richtlinien 4 und 5 zum Verfahren fur die Bewahrung von Namen.

\section{Empfehlung 15ám}

Wenn die Änderung der diagnostischen Merkmale bei der Umgrenzung eines Taxons erheblich war, durfen die Art der Anderung und der verantwortliche Autor durch Hinzufügung passender Abkürzungen, wie emend. (emendavit), mut. char., excl. gen., excl. spec., etc. kenntlich gemacht werden.

\section{Empfehlung 15b.}

Wenn ein Name mit einer Beschreibung oder mit Bezugnahme auf die Beschreibung eines Autors in der Arbeit eines anderen Autors veroffentlicht wird, sollte das Wort in als Verbindung zwischen den Namen der beiden Autoren benutzt werden.

\section{Empfehlung 15c.}

Wenn eine Veroffentlichung von mehreren Autoren Namen von Taxa enthalt, deren Autorenschaft zitiert werden soll, ist es dringend nötig, dass einer der Autoren endgultig für die Zitierung als Autor bezeichnet wird.

RegeL 16.

Wenn eine Gattung, Untergattung, eine Art oder eine Unterart (Varietat) sich in der Rangstufe andert, aber seinen (ihren) Namen oder Epitheton beibehălt, muss der ursprung liche Autor zitiert werden, gefolgt von dem Namen des Autors, der die Änderung vornahm. Gleiches gilt, wenn eine Untergattung, eine Art oder eine Unterart (Varietät) in eine andere Gattung oder eine andere Art mit oder ohne $\ddot{A}$ nderung der Rangstufe therfuhrt werden. 
Empfehlung $16 a$.

Beim Zitieren eines Namens, der als Synonym veroffentlicht wurde, sollten die Worte "als Synonym" oder "pro synon." dem Zitat folgen.

Wenn ein Autor einen Namen aus dem Manuskript eines anderen Autors als Synonym veroffentlicht hat, sollte das Wort "ex" zur Verbindung der beiden Autorennamen benutzt werden.

Empfehlung 16b.

Wenn in der Synonymie ein Name zitiert wird, der durch ein fruheres Homonym ungthlig geworden ist, sollte dem Zitat der Autorenname des fruheren Homonyms folgen; doch muss vor diesem das Wort "non", am besten zusammen mit dem Zeitpunkt der Veroffentlichung stehen. In manchen Fallen wird es ratsam sein, auch jedes spatere Homonym zu zitieren.

Empfehlung 16c.

Beim Zitieren eines Nomen nudum sollte sein Status durch das Zitat nom. nud. angezeigt werden.

Empfehlung 16d.

Falls ein Gattungsname, dem gleichzeitig eines seiner Synonyme oder ein Homonym vorausgeht, als ein Nomen conservandum anerkannt wird sollte die Abkurzung nom. cons. dem Zitat zugefugt werden.

Empfehlung 16e.

Als Synonym zitierte Namen sollten genau so, wie von ihren Autoren veroffentlicht, buchstabiert werden. Falls irgendwelche erklärenden Worte benotigt werden, sollten diese in Eckklammern eingefugt werden. Falls ein Name mit Änderungen von der ursprelnglich veroffentlichten Form angenommen wird, ist es winschenswert, dass im vollen Zitat die genaue Originalform hinzugefügt wird. 


\section{Sektion 5.}

Namensănderungen als Ergebnis von Aufteilung, Vereinigung oder Änderung im Rang von Taxa.

\section{Regel 17a.}

Eine Änderung der diagnostischen Merkmale oder der Abgrenzung eines Taxons berechtigen einen Namenswechsel nicht, ausgenommen der Fall, dass dies durch die Überfuhrung des Taxons, durch seine Vereinigung mit einem anderen Taxon der gleichen Rangstufe (Regel 19) oder eine Änderung seiner Rangstufe (Regel 22) erforderlich wird.

\section{Regel 17b.}

Wenn eine Gattung in zwei oder mehrere Gattungen aufge teilt wird, muss der Gattungsname für eine der beiden beibehalten oder (falls er nicht beibehalten worden ist) wieder eingesetzt werden. Wenn eine besondere Art urspranglich als Typ bezeichnet wurde, muss der Gattungs name fur diejenige Gattung beibehalten werden, die die betreffende Art einschliesst. Wenn kein Typ bezeichnet wurde, muss ein Typ ausgewählt werden. Die gleiche Regel wird angewandt, wenn eine Untergattung in zwei oder mehrere Untergattungen aufgeteilt wird.

\section{Regel 17c.}

Der Name eines Taxons muss geändert werden, wenn der Nomenklaturtyp des Taxons ausgeschlossen wird.

\section{Regel 18a.}

Wenn eine Art in zwei oder mehrere Arten geteilt wird, muss das spezifische Epitheton fur eine der beiden beibehalten oder (falls es nicht beibehalten wurde) wieder einge fuhrt werden. Wenn ein Typ für die Art bezeichnet worden ist, muss das spezifische E pitheton für die jenige Art beibehalten werden, zu der dieser Typ gehort. Wenn kein Typ bezeichnet wurde, muss einer ausgewahlt werden.

Dieselbe Regel gilt furr Unterarten (Varietäten); z.B. fur eine Unterart (Varietas), die in zwei oder mehrere Unterarten (Varietäten) aufgeteilt wird. 
Regel 18b.

Wenn eine Art in eine andere Gattung uberfuhrt (oder unter einem anderen Gattungsnamen in die gleiche Gattung gestellt)wird, ohne dass sich die Rangstufe ändert, muss das spezifische Epitheton beibehalten oder (falls es nicht beihalten worden ist) wieder eingefthrt werden, sofern nicht einer der folgenden Hinderungsgrunde besteht:

1) Der sich ergebende binăre Name ist ein spateres Homonym oder Tautonym oder

2) ein anderes gultig publiziertes spezifisches Epitheton ist verfugber.

Wenn das spezifische Epitheton bei der Überfuhrung in einen anderen Gattungsnamen in seiner neuen Stellung fälschlich einer anderen Art zugeteilt wurde, muss die neue Kombination fur den Keim beibehalten werden, auf den das Epitheton ursprunglich zuruckging.

\section{Regel 19.}

Wenn zwei oder mehrere Taxa der gleichen Rangstufe vereinigt werden, wird der alteste regelmăssige Name (oder bei Art und Unterart) das alteste regelmásige Epitheton beibehalten. Wenn die Namen oder Epitheta gleichen Datums sind, hat der Autor, der als erster die Vereinigung der Taxa vornimmt, das Recht, einen (eines) davon zu wahlen. Seiner Waht ist zu folgen.

Empfehlung 19a.

Autoren, die zwischen zwei Gattungsnamen zu wahlen haben, sollten die folgenden Empfehlungen beachten:

1) Von zwei Namen desselben Datums sollten sie den vorziehen, der als erster mit einer Artbeschreibung einherging.

2) Von zwei Namen desselben Datums, die beide mit einer Artbeschreibung einhergehen, sollte bei der Wahl durch den Autor derjenige Vorzug haben, der die grossere Zahl von Arten einschliesst.

3) Im Falle, dass hinsichtlich der verschiedenen Gesichtspunkte Gleichheit besteht, sollte der passendere Name bevorzugt werden. 
Regel 20.

Wenn mehrere Gattungen als Untergattungen unter einem Gattungsnamen vereinigt werden, muss die Untergattung, "die den Typ des benutzten Gattungsnamens einschliesst, den Namen unverändert beibehalten.

\section{Regel 21.}

Wenn mehrere Arten als Unterarten (Varietăten) unter einem Artnamen vereinigt werden, oder wenn eine Art in Unterarten aufgeteilt wird, muss die Unterart, die den Typ der Art einschliesst, mit dem gleichen Epitheton bezeichnet werden wie die Art.

\section{A nmerkung 1.}

Der Vorschlag eines Namens einer Unterart, der den Typ der Art ausschliesst, hat automatisch einen anderen Namen einer Unterart zur Folge, der den Typ einschliesst. Der Autor des Artnamens ist als Autor eines solchen automatisch anerkannten Namens einer Unterart zu zitieren.

\section{Anmerkung 2.}

Die Schiedskommission ist ermächtigt, Ausnahmen von der Regel zu machen, wenn ein gut eingefuhrter Name einer Unterart nicht im Einklang mit der Regel steht.

\section{Regel 22a.}

Wenn ein Taxon mit der Rangstufe oberhalb einer Gattung, aber nicht hoher als eine Ordnung seine Rangstu fe ändert, muss der Stamm des Namens beibehalten und nur das Suffix geändert werden (-inae, -eae, -oideae, -aceae, -ineae, -ales), sofern der Name nicht gemäss den Bestimmungen der Sektion 6 verworfen werden muss.

\section{Regel 22b.}

Wenn eine Untergattung zur Gattung oder eine Gattung zur Untergattung wird, muss der ursprungliche Name beibehalten werden, wenn er nicht gemäss den Bestimmungen der Sektion 6 verworfen wird. 
$\underline{\text { Regel 22c. }}$

Wenn eine Unterart (Varietät) zu einer Art oder eine Art zu einer Unterart (Varietăt) wird, sollte das ursprüngliche Epitheton beibehalten werden, sofern die daraus entstehende Kombination nicht gemäss den Bestimmungen in Sektion 6 verworfen wird.

\section{Sektion-6}

Zurückweisung und Ersatz von Namen.

\section{Regel 23.}

Ein regelmässiger Name oder spezifisches Epitheton darf nicht nur deshalb verworfen werden, weil er unangemessen oder unangenehm, oder weil ein anderer vorzuiehen oder besser bekannt ist, oder weil er seine ursprung liche Bedeutung verloren hat.

\section{Regel 24.}

Ein Name muss zurulckgewiesen werden, wenn er regelwidrig ist, d.h. wenn er einer Regel widerspricht. Ein regelwidriges Epitheton darf fur Prioritätszwecke nicht in Betracht gezogen werden. Der Name eines Taxons ist regelwidrig:

a) Wenn er bei seiner Veroffentlichung nomenklatorisch überfliussig war, d. h. wenn das Taxon, dem er beigegeben war, nach der Abgrenzung durch seinen Autor bereits den Typ eines Namens enthielt. den der Autor selbst nach einer oder mehreren Regeln hätte ubernehmen sollen.

b) Falls er ein binärer oder ternärer Name ist, der im Widerspruch zum Grundsatz 9 und den Regeln 17 - 23 steht, d.h. wenn sein Autor nicht den fruhesten regelmässigen Gattungsnamen bzw. das fruheste regelmässige spezifische oder subspezifische Epitheton ubernahm, der (bzw. das) fur das Taxon mit seiner besonderen Abgrenzung Stellung und Rangstufe verfügbar war (S. Anmerkung żu Regel 26).

c) Wenn ein spezifisches Epitheton gemäss Regel 25 verworfen werden muss.

d) Wenn er ein späteres Homonym eines Taxonnamens aus dem Bereich der Bakterien, Pilze, Algen, Viren 
oder Protozoen darstellt, d.h. wenn dadurch ein Name wiederholt wird, der vorher gültig fur ein Taxon der gleichen Rangstufe, aber basierend auf einem anderen Typ, veroffentlicht wurde. Selbst wenn das frthere Homonym regelwidrig ist oder aus taxonomischen Grunden allgemein als ein Synonym behandelt wird, muss das spätere Homonym verworfen werden. Wenn ein Autor gleichzeitig den selben neuen Namen fur mehr als ein Taxon veroffentlicht, ist dem ersten Autor zu folgen, der einen davon annimmt oder einen von ihnen durch einen anderen Namen ersetzt.

Anmerkung:

Blosse orthographische Unterschiede desselben Namens werden als homonym behandelt, wenn sie auf verschiedenen Typen begrandet sind.

e) Wenn er mit verschiedenen Bedeutungen benutzt und somit zur ständigen Quelle von Irrtümern ge worden ist. Eine Liste von Namen (nomina ambigua), die aus diesem Grunde aufgegeben werden mússen, wird in die Liste der nomina rejicienda einbezogen werden.

f) Wenn seine Anwendung unsicher ist (nomen dubium). Eine Liste von Namen, die aus diesem Grunde aufgegeben werden mussen, wird in die Liste der Nomina rejicienda aufgenommen werden.

Empfehlung 24a.

Autoren sollten für Gattungsbezeichnungen in die Bakteriologie die Einführung solcher Namen vermeiden, die in der Botanik oder Zoologie bereits verwendet werden.

Regel 25.

Ein spezifisches oder subspezifisches Epitheton ist in den folgenden besonderen Făllen regelwidrig und zu verwerfen:

a) Wenn solch ein Epitheton lediglich ein Wort darstellt, dessen Gebrauch als spezifisches Epitheton nicht beabsichtigt war.

b) Wenn solch ein Epitheton lediglich ein Zahlwort darstellt, das zur Aufzählung dient. 
c) Wenn ein solches Epitheton genau den Gattungsnamen wiederholt (Tautonym).

\section{Anmerkung:}

Wiederholung des Namens einer Gattung in einem anderen Casus sollte vermieden werden (z.B. Arizona arizonae).

d) Wenn ein solches Epitheton ein späteres Homonym innerhalb der gleichen Gattung darstellt, d.h. wenn es ein spezifisches oder subspezifisches Epitheton wiederholt, das vorher gultig fur eine Art oder Unterart der gleichen Gattung, doch basierend auf einem anderen Typ, veroffentlicht wurde.

\section{Anmerkung:}

Ein spezifisches Epitheton wird nicht dadurch regelmässig, dass es in einem Artnamen veroffentlicht wird, in dem der Gattungsname regelwidrig ist.

Regel 26.

Der Name oder das Epitheton, die gemäss Regel 23 - 25 zu verwerfen sind, werden durch den ältesten regelmäs sigen Namen ersetzt, oder (in einer Kombination) durch das ălteste regelmässige Epitheton, der (das) in der neuen Position mit den Regeln im Einklang steht. Bei Nichtvor handensein muss ein neuer Name bzw. ein neues Epitheton ausgewåhlt werden.

\section{Anmerkung:}

Wenn ein neues Epitheton benbtigt wird, darf ein Autor, wenn er will, ein legitimes Epitheton ubernehmen, das dem Taxon vorher (in einer regelwidrigen Kombination) gegeben wurde, vorausgesetzt, dass seinem Gebrauch in der neuen Stellung oder im neuen Sinn nichts im Wege steht. Die so entstehende Kombination wird als neuer Name behandelt und seinem Autor zugeschrieben.

\section{Sektion 7.}

Rechtschreibung und Gescklecht von Namen und Epitheta. Regel 27.

Die ursprungliche Schreibung eines Namens oder Epithe- 
tons muss beibehalten werden, ausgenommen typographische, oder orthographische Fehler. Wenn zwei oder mehr Gattungsnamen oder zwei oder mehr spezifische Epitheta innerhalb derselben Gattung so ähnlich sind, dass sie zu Verwechslung führen, werden sie als orthographische Variante desselben Namens oder Epithetons behandelt.

\section{Anmerkung 1:}

Der Ausdruck "ursprtingliche Schreibweise", wie sie in dieser Regel gebraucht wird, bedeutet die Schreibweise, die angewandt wurde, als man den Namen des Taxons gultig veroffentlichte. Sie bezieht sich nicht auf den Gebrauch eines grossen oder kleinen Anfangsbuchstabens. Adjektive, die als spezifische oder subspezifische Epitheta benutzt werden, ändern notigenfalls ihre Endungen, um mit dem Geschlecht des Gattungsnamens ubereinzustimmen.

\section{Anmerkung 2:}

Durch die Benutzung eines falschen (oder alternativ) gebrauchten Bindevoka ls bzw. von Bindevokalen (oder die Weglassung eines Bindevokals) in einem Gattungs - oder Untergattungsnamen oder in einem spezifischen oder subspezifischen Epitheton, entsteht eine orthographische Variante.

\section{Anmerkung 3:}

Wenn Zweifel besteht, ob die Schreibung der Namen von zwei ranggleichen Taxa oder von zwei Epitheta hinreichend thnlich ist, um verwechselt zu werden, sollte die Ange tegenheit der Schiedskommission zur Abgabe einer Meinungs ausserung zugeleitet werden.

\section{Anmerkung 4:}

Ein unbeabsichtigter typographischer oder orthographischer Fehler, der später vom Autor korrigiert wird, soll in seiner berichtigten Form ohne Beeinträchtigung hinsichtlich des ursprunglichen Datums und der Gultigkeit der Veroffentlichung akzeptiert werden.

\section{Anmerkung 5:}

Die Schreibweise des Namens eines Taxons oder Epithe- 
tons, das zwar vom Griechischen abgeleitet, aber von seinem Autor nicht im Einklang mit dem klassischen Regeln (Appendix A) latinisiert wurde, kann als orthograpnischer Fehler von der Schiedskommission berichtigt und in die Liste der vorzuziehenden Schreibweisen (vergl. Empfeh lung 27a) eingereiht werden. Der Name des Taxons in seiner ursprünglich veroffentlichten Form wird zu einer orthographischen Variante des berichtigten Namens, jedoch ohne Beeinträchtigung hinsichtlich der Gultigkeit seiner Veroffentlichung durch den ersten Autor. Spezifische und andere Epitheta sowie Namen griechischer Herkunft, die sich lediglich im Geschlecht durch griechische oder lateinische Endungen unterscheiden, 's ind orthographische Varianten. Epitheta mit derselben. Bedeutung und nur geringen Formenunterschieden werden als orthographische Varianten angesehen. Die Genetiv - und Adjektivformen eines Personennamens werden jedoch als verschiedene Epitheta behandelt.

\section{Anmerkung 6:}

Namen von Taxa und spezifische Epitheta sind oft zusammengesetzte Worte, manchmal mit lateinischen, häufiger mit griechischen Wortstämmen, gelegentlich (weniger richtig) aus Wortstämmen zweier verschiedener Sprachen. Solche zusammengesetzte Worte, die aus gleichen Wortstämmen gebildet werden, unterscheiden sich manchmal nur im Bindevokal:

a) Bei der Bildung zusammengesetzter Namen von Taxa und spezifischer Epitheta aus dem Lateinischen lautet der Bindevokal -i-. Zysammengesetzte Worte, die sich in der Schreibweise nur durch den Bindevokal -i- oder -o- unterscheiden, sollen als orthographische Varianten angesehen werden. Namen von Taxa, die solche orthographischen Varianten darstellen und sich auf verschiedene Typen statzen, sind als Homonyme anzusehen. Die Schreibweise fur jedes Taxon und spezifische Epitheton sollte derjenigen entsprechen, die vom Autor bei der gültigen Veroffentlichung des zusammengesetzten Namens benutzt wurde.

b) Der Bindevokal in zusammengesetzten worten griechischer Herkunft, bei denen der erste Wortteil aus einem Hauptwort oder Adjektiv besteht, lautet meistens -o-.. Er kann weggelassen werden, wenn 
der zweite Wortteil mit einem Vokal beginnt. Er wird weggelassen, wenn der erste Wortteil auf -y-endet (glycyphyllus). Ein anderer Bindevokal kann benutzt werden, wenn es einen guten griechischen Präzèdenzfall gibt, z: B. wie bei Coryne bacterium.

Namen von Taxa oder Worte, die als spezifische Epitheta benutzt werden und die aus dem Griechischen zusammengesetzt sind und sich nur durch Vorhandensein oder Fehlen des Bindevokals -o- unterscheiden oder einen anderen Bindevokal besitzen, sind als orthographische Varianten zu betrachten. Wenn die Namen von Taxa auf verschiedenen Typen begrundet sind, sind sie als Homonyme anzusehen. Die richtige Schreibung ist diejenige des Taxonnamens oder des spezifischen Epithetons, die vom Autor bei der ersten und gultigen Ver bffentlichung benutzt wurde.

c) Zusammengesetzte Worte aus zwei oder mehr verschiedenen Sprachen (nomina hybrida) sind als orthographische Varianten anzusehen, wenn sie sich nur im Bindevokal unterscheiden. Die Schreibung, die zuerst von einem Autor in der ersten gultigen Veroffentlichung benutzt wurde, sollte Vorrang haben. Wenn die zwei Wortteile Namen von Taxa mit verschiedenen Typen sind, werden sie als Homonyme angesehen.

\section{Anmerkung 7:}

Die Freiheit, einen Namen oder ein Epitheton zu berichtigen, soll mit Zuruckhaltung benutzt werden, besonders wenn die Änderung die erste Silbe betrifft und vor allem den ersten Buch staben des Namens oder Epithetons.

\section{Anmerkung 8:}

Absichtliche Latinisierungen, die Änderungen in der Orthographie von Personennamen in sich schliessen, vor allen Dingen solche fruherer Autoren, mussen erhalten werden.

\section{Anmerkung 9:}

Diakritische Zeichen (fur Umlaute, Akzente etc.) werden 
in der Bakteriologie nicht für Namen oder spezifische Epitheta benuzt. Bei Namen oder Epitheta, die sich von Worten mit solchen diakritischen Zeichen ableiten, müsen diese weggelassen und die Buchstaben, wie folgt, umschreiben werden:

L) $\underline{a}, \underline{b}$, und $\underline{\underline{u}}$ werden zu ae, oe und ue (deutsch),

2) $\bar{e}, \underline{e}$ worden zu e (franzosisch),

3) o (ठ) , ae (a) und a werden zu oe, ae und aa (skandinavisch).

Wenn Doppellaute nicht durch eine spezielle Type kenntlich gemacht werden, sollen erforderlichenfalls Trennzeichen benutzt werden, um zu zeigen, dass zwei aufeinanderfolgende Vokale getrennt ausgesprochen werden (also zu zwei Silben gehøren).

\section{Anmerkung 10:}

Bestimmte Konsonanten, die im klassischen Latein nicht vorkommen, nämlich w, $y$ und das selten benutzte $k$, konnen in der Bakteriologie fur Taxonnamen und spezifische Epitheta gebraucht werden.

\section{Empfehlung 27a.}

Wenn ein Name oder Epitheton für seine Anwendung in der bakteriologischen Nomenklatur von einem griechischen Wort abgeleitet wird, sollte seine Latinisierung den klassischen Regelm entsprechen. Appendix A (siehe oben) dieses Kodex kann hierzu als Wegweiser dienen. Falls ein späterer Autor in einer gultigen Veroffentlichung die Schreibweise eines Namens oder Epithetons berichtigt, das nicht korrekt aus dem Griechischen latinisiert wurde, moge das richtig geschriebene Wort als orthographische Variante des Namens oder Epithetons angesehen werden.

Empfehlung 27b.

Wenn es notig ist, zwischen Worten zu wählen, die als Taxonnamen oder als spezifische bzw. subspezifische Epitheta gultig veroffentlicht sind und sich in der Schreibweise nur infolge fehlerhafter oder alternativer Latinisierung aus dem Griechischen unterscheiden, wird empfohlen, dass die Wahl durch die Richtlinien des Appendix $\mathbf{A}$ und $\mathbf{B}$ dieses Kodex (siehe oben) bestimmt wird. Das Gleiche gilt fur die Worte mit alternativer Überfuhrung von Endungen, 
die das Geschlecht oder abhängige Fălle (besonders den Genetiv) bezeichen.

Empfehlung 27c.

Für wissenschaftliche Taxonnamen ist es ratsam, eine andere Schriftype zu benutzen als die im ubrigen Text oder Sperrdruck oder ein anderes textgemässe.s Hilfsmittel. Wissenschaftliche Namen in Schreibma schinenschrift sollten unterstrichen werden als Hinweis, dass sie beim Druck in einer anderen Satztype, vorzugsweise Kursivschrift, erscheinen sollen.

Empfehlung 27d.

Wenn ein neuer Name für eine Gattung oder Unterga ttung vom Namen einer Person abgeleitet wird, sollte er in folgender Weise gebildet werden:

1) Wenn der Name der Person mit einem Vokal oder $\mathrm{y}$ endet, wird đer $\mathrm{Buchstabe}$ a angehăngt; endet der Name der Person jedoch mit a, wird ea angehängt.

2) Wenn der Name einer Person mit einem Konsonanten endet, werden die Buchstaben ia angehängt, ausgenommen die Endungen er; dann wird ein a angehăngt.

3) Wenn der Name einer Person latinisiert worden ist und mit us endet, wird vor Anhängung des. Suffixes diese Endung weggelassen.

4) Der Name einer Bakterien-Gattung oder -Untergattung kann aus dem Namen einer Person durch Anhängung einer Diminutivendung gebildet werden.

5) Die Silben, die durch diese Endungen nicht verändert werden, behalten ihre ursprungliche Schreibweise, selbst mit den Konsonantan $\underline{k}$ und $\underline{w}$ oder Gruppen von Vokalen und Konsonanten, die im klassischen Latein nicht gebraucht werden.

\section{Empfehlung 27e.}

Ein neues spezifisches oder subspezifisches (varietätsbezeichnendes) Epitheton, das von einem Männernamen abgeleitet wird, kann entweder Substantiv-oder Adjektiv charakter annehmen. Wenn das Epitheton ein Substantiv ist, wird der modernisierte lateinische Genetiv auf folgende Weise gebildet:

1) Wenn der Name einer Person mit einem Vokal oder 
mit y endet, wird der Buchstabe -í- angehängt.

2) Wenn der Name mit einem Konsonanten endet, werden die Buchstaben -ii - angehängt (also welchii aus Welch), ausgenommen bei Endungen der Namen auf er; dann wird -i - angehängt (also barkeri aus Barker).

3) Wenn der Personenname bereits lateinisch oder griechisch oder latinisiert worden ist, sollte der entsprechend lateinische Genetiv benutzt werden.

4) Die Silben, die durch diese Endungen nicht geändert werden, behalten ihre ursprungliche Schreibweise, selbst mit den Konsonanten, die im klassischen Latein nicht gebraucht werden. Wenn das Epitheton ein Adjektiv ist, wird es durch Anhängen einer entsprechenden Endung gebildet.

Empfehlung 27f.

Die Richtlinien der Empfehlung 27 e gelten auch fur ein Epitheton das aus einem Frauennamen hergeleitet wird.

Wenn das Epitheton Hauptwortcharakter hat, erhălt es eine weibliche Endung.

Empfehtung 27g.

Ein neues spezifisches oder subspezifisches Epitheton sollte im Einklang mit der ursprunglichen Schreibweise des Wortes geschrieben werden, von dem es abgeleitet ist, sowie in strenger Übereinstimmung mit den Regeln des Lateins und der Latinisierung.

Empfehlung 27h.

Ein spezifisches Epitheton - selbst wenn es sich von Personennamen herleitet - sollte nicht mit einem grossen Anfangsbuchstaben geschrieben werden.

Empfehlung 27i.

Autoren sollten die Etymologie neuer Gattungsamen und auch die neuer Epitheta angeben, wenn deren Bedeutung nicht offensichtlich ist.

Empfehlung 27k.

Worte, die von Sprachen hergeleitet sind, die das 
lateinische $A$ lphabet benutzen und ins Lateinische transskribiert und latinisiert werden, sind als orthographische Varianten anzusehen, wenn sie sich nur durch die Transskription unterscheiden. Solche orthographische Varianten, die als Taxonnamen benutzt werden und auf verschiedenen Typen basieren, sind als Homonyme anzusehen.

\section{Empfehlung 27L.}

Taxonnamen und spezifische Epitheta, die sich nur durch Anwesenheit oder Fehlen von diakritischen Zeichen, Transskription des deutschen Umlauts oder Benutzung besonderer Buchstaben unterscheiden, sind als orthographische Varianten anzusehen. Wenn sie sich auf verschiedene Typen stutzen, sollten sie als Homonyme behandelt werden. Worte, die nicht im Einklang mit Regel 27, Anmerkung 9 gebildet sind, kơnnen berichtigt werden.

\section{Empfehlung $27 \mathrm{~m}$.}

Ein N.ame oder ein Epitheton, das von einem nicht lateinischen oder nicht griechischen Wort abgeleitet wird und keine Endung besitzt, die einer der lateinischen $\mathrm{De}$ klinationen entspricht und das nicht durch Anhängen einer lateinischen Endung latinisiert worden ist, soll als ein nicht deklinierbares lateinisches Hauptwort angesehen werden. Zwei odér mehrere Namen oder spezifische Epitheta, die sich vom gleichen Wort herleiten, einer mit, der andere ohne lateinische Endung, sind orthographische Varianten. Wenn die Namen von Taxa auf verschiedenen Typen basieren, sollten sie als Homonyme behandelt werden.

\section{Empfehlung 27n.}

Autoren von neuen Taxonnamen oder von spezifischen bzw. subspezifischen Epitheta, die sich vom Griechischen herleiten, werden dringend ersucht, sich bein Latinisieren von Worten oder Wortstämmen strikt an die Empfehlungen in Appendix A zu halten.

\section{Empfehlung 27o.}

Der Name einer Gattung sollte ohne Abkurzung ausge schrieben werden wenn er in einer Veroffentlichung zum 
ersten Mal mit einem spezifischen. Epitheton benannt wird (z.B. Serratia marcescens), ausgenommen, dass es in einer Serie von Artnamen der gleichen Gattung ublich ist, den Gattungsnamen in allen Artnamen nach dem ersten abzukurzen. Bei späterer Benutzung des Artnamens, der schon vorher zitiert wurde, wird der Gattungsname gewohnlich abgekurzt. Die gebrauchliche Abkurzung des Gattungsnamens in einem Artnamen ist gewöhnlich der erste Buchstabe des Gattungsnamens (z.B. S. marcescens). In Veroffentlichungen, in denen Arten aufgefuhrt werden, die zu zwei oder mehr Gattungen mit dem gleichen Anfangsbuchstaben gehoren, ist bei der Abkürung von Namen Vorsicht geboten, damit Verwechslungen vermieden werden.

Regel 28.

Das Geschlecht von Gattungsnamen wird von folgenden Vorschriften bestimmt:

a) Ein als Gattungsname angenommenes lateinisches oder griechisches Wort behălt sein ursprungliches Geschlecht. In Fällen, in denen das ursprangliche Geschlecht wechselt, hat der Autor das Recht der Wahl zwischen den alternativen Geschlechtern. Im Zweifel sollte der ublichen Anwendungsweise gefolgt werden.

b) Gattungs - und Untergattungsnamen, die neu aus zwei oder mehr griechischen oder lateinischen Worten zusammengesetzt sind, nehmen das Geschlect des letzten Wartes an. Wenn die Endung geändert wird, folgt das Geschlecht der neuen Endung in der Sprache seiner Herkunft.

c) Willkürlich gebildete Gattungsnamen oder Namen in der Landesspache die als Gattungsnamen benutzt werden, nehmen das ihnen von ihrem Autor zugewiesene Geschlecht an. Wenn dar ursprungliche Autor das Geschlecht nicht bezeichnet hat, hat der nächstfo'lgende Autor das Recht der Wahl.

\section{KAPITEL 4 .}

Vorschriften fur die Organisation und Verwaltung des Internationalen Kodex fur die Nomenklatur der Bakterien und für die Auslegung und Verânderung seiner Regeln. 
Vorschrift 1

Veränderung des Kodex

Dieser Kodex kann nur durch Massnahmen des International Committee on Nomenclature of Bacteria und durch Billigung der Hauptversammlung eines von der I. A. M.S. veranstalteten Internationalen Mikrobiologenkongresses geändert werden.

Vorschrift 2

Listen der Nomina conservanda.

Zur Vermeidung nachteiliger Änderungen in der Nomenklatur der Taxa infolge strikter Anwendung der Nomenklatur-Regeln, sehen die Regeln eine Liste von Namen vor, die als Ausnahmen bewahrt werden müssen (nomina conservanda).

\section{Anmerkung 1.}

Diese Liste zu konservierender Namen wird ständig für Erweiterungen offenbleiben. Jeder Vorschlag fur einen zusatzlichen Namen muss zusammen mit einer detaillierten Erläuterung des Fur und Wider der Namenserhaltung eingereicht werden. Solche Vorschläge sind der Scheid kommission (vergl. Vorschrift 4) zur Prufung und Einleitung entsprechender Massnahmen vorzulegen.

\section{Anmerkung 2.}

Wenn ein zur Beibehaltung vorgeschlagener Name von der Schiedskommission provisorisch gebilligt ist, haben die Bakteriologen das Recht, ihn - vorbehaltlich der Entscheidung des nächsten Internationalen Mikrobiologenkongresses - zu gebrauchen.

\section{Anmerkung 3.}

Ein konservierter Name ist gegenuber allen anderen Namen des betreffenden Taxonsi geschitzt, gleichgültig, ob diese in der entsprechenden Liste der zurückgewiesenen Namen aufgefuhrt sind oder nicht, und zwar so lange wie das betreffende Taxon nicht mit einem anderen Taxon, das einen legitimen Namen trägt, vereinigt wird. Im Fall der Vereinigung oder Wiedervereinigung mit einem anderen Taxon wird der fruhere der beiden konkurrierenden Namen 
im Einklang mit Regeln 19, 20 und 21 angenommen.

Anmerkung 4.

Ein konservierter Name ist gegenuber allen fruheren Homonymen gescheitzt.

Vorschrift 3.

Listen der Nomina rejicienda.

Zur Vermeidung unnotiger Verwirrung in der Nomenklatur der Bakterien infolge strikter Anwendung der Nomenklaturregeln sehen die Regeln eine Liste von Namen vor (nomina rejicienda), die nicht benutzt, d.h. fur immer zurackgewiesen.. werden sollen. Diese Liste beinhaltet Namen, die infolge Absplitterung mit verschiedenen Bedeutungen benutzt werden und eine ständige Quelle von Irrtumern und Verwechslungen geworden sind (nomina ambigua), Namen deren $B$ enutzung unsicher ist (nomina dubia) und Namen, die einer Gruppe aus zwei oder mehreren nicht zusammengehorigen Elementen verliehen wurden, vor allem, wenn von diesen Elementen irrigerweise angenommen wurde, dass sie Teile des gleichen Einzelwesens bilden (nomina confusa).

Anmerkung 1.

Die Liste zurückgewiesener Namen wird ständig für eine Erweiterung offenbleiben. Jeder Vorschlag fur die Zufugung eines Namens muss zusammen mit einer detaillierten Erläuterung des $F u r$ und Whder der Verwerfung des Namens im betreffenden Falle eingereicht werden. Solche Vorschläge sind der Schiedskommission des ICNB zur Prufung und Einleitung geeigneter Schritte vorzulegen. Wenn ein zur Abweisung vorgeschlagener Name von der Schiedskommission provisorisch verworfen worden ist, haben die Bakteriologen das Recht, den Namen zurackzuweisen - vorbehaltlich der Entscheidung das nachfolgenden Internationalen Mikrobiologenkongresses.

\section{Anmerkung 2,}

Ein einmal verworfener Name darf spater nicht mehr legitim in die bakteriologische Literatur eingefuhrt werden. Ausgenommen sind nomina dubia. Diese konnen von der 
Liste gestrichen werden, wenn Beweise fur den richtigen Status beigebracht werden, ferner durch Massnahmen der Schiedskommis sion.

Vorschrift 4.

Ständiges Internationales Komitee fur die Nomenklatur der Bakterien.

Ein ständiges Internationales Komitee fur die Nornenklatur der Bakterien ist von der tagenden Internationalen Vereinigung der Mikrobiologischen Gesellschaften gegrundet worden. Dieses Komitee ist so zusammengesetzt, dass - wo immer sinnvoll - jedes Land durch mindestens ein Mitglied, aber kein Land durch mehr als füf Mitglieder vertreten ist. Nominierungen für die Mitgliedschaft erfolgen vorzugsweise in jeder Nation durch diejenige mikrobiologische Gesellschaft, die als nationales Mitglied der Internationalen Vereinigung der mikrobiologischen Gesellsieháften'(IAMS) fungiert. Der Begriff des nationalen Mitglieds ist in Artikel 3 der Statuten der IAMS, 1952 definiert. Nominierungen sollen schriftlich bei einem der ständigen Sekretäre des Komitees eingereicht werden. Die Annahme wird durch den Sekretär kund getan, und der Nominierte wird zeitweilig Mitglied des Komitees, vorbehaltlich weiterer Schritte des Komitees und des nächstfol genden Internationalen Kongresses, bei dem die Wahl bestatigt wird. Falls entsprechende nationale oder regionale mikrobiologische Gesellschaften oder Organisationen nicht bestehen, kann eine primäre Nominierung fur ein nicht vertretenes Land durch einen der ständigen Sekretăre erfolgen. Nach seiner Wahl soll solch ein Mitglied die Tatigkeit solange ausuben; bis Nominierurgen durch eine nationale oder regionale mikrobiologische Gesellschaft erfolgt sind. Die Mitgliedschaft im Internationalen Komitee ist unbegrenzt. Sie kann durch Rucktritt, Tod, Ersuchen der nominierenden Organisation oder durch ständige Nichtteitnahme en der Komiteearbeit beendet werden. Vor jedem Kongress soll jede nationale Gesell'schaft die ständigen Sekretäre uber jegliche Empfehlungen betreffs Wechsel in der Vertretung unterrichten.

\section{Anerkennung von Vertretern:}

Falls ein Mitglied des ICNB an den Kommissionsversammlungen nicht teilnehmen kann, wird ein Vertreter 
mit allen Rechten eines berufenen Mitglieds - ausgenommen das Recht zur Wahl des Vorstandes und von Kommissionsmitgliedern. - im Einklang mit folgenden Prinzipien ausgewählt:

a) Die nationale mikrobiologische Gesellschaft, die das Mitglied vertritt, soll das Recht haben, einen Vertreter zu benennen.

b) Falls durch die nationale Gesellschaft keine Nominie rung erfolgt, soll das Mitglied selbst das Recht haben, einen Vertreter zu benennen.

c) Falls weder die nationale Gesellschaft noch das Mitglied einen Vertreter benennen, kann der Vor sitzende des Komitees mit den ständigen Sekretăren nominieren. Alle Nominierungen fur Vertreter durch nationale Gesellschaften oder durch Mitglieder sollen schriftlich erfolgen und vor der ersten Zusammenkunft des Komitees bei einem der stăndigen Sekretăre vorliegen. Alle Nominierungen von Vertretern sollen auf der ersten Zusammenkunft des Komitees vorgelegt werden. Nominierte, die durch Abstimmung der Kommission gewählt sind, werden als̉ Vertreter tătig sein.

Aufgaben des Internationa Len Komitees.

Das International Committee on Nomenclature of Bacteria (ICNB)

1) Es soll Zusammenkunfte zum Zeitpunkt. und als Teil der Sitzungen jedes Kongresses der International Association of Microbiolgical Societies (IAMS) abhalten.

2) Es soll alle Empfehlungen der Schiedskommission hinsichtlich der Formulierung, Änderung oder Verbesserung des Internationalen Kodex fur die Nomenklatur dér Bakterien oder bezuglich der Nomenklatur anderer Gruppen, die die Mikrobiologie betreffen, uberdenken und uber sie entscheiden. In Fällen; in denen die Billigung der IAMS ebenfalls benutigt wird, soll das Komitee die entsprechenden Empfehlungen ausarbeiten. Vorschlage fur die Verbesserung des bakteriologischen Kodex sollen einem der ständigen Sekretäre recht zeitg vorher eingereicht werden, damit sie vor dem nåchstfolgenden Internationa len Mikrobiologenkongress im International Journal of Systematic Bacteriology veroffentlicht werden konnen.

3) Es soll alle in der Schiedskommission abgegebenen 
Meinungsăusserungen entgegennehmen. Jede Meinungsăusserung der Schiedskommission ist endultig, wenn kein formeller Widerspruch erhoben wird. In diesem Falle soll das ICNB uber die Annahme oder Ablehnung bestimmen oder andere geeignete Schritte unternehmen. Das Internationale Komitee soll bei der năchsten Komiteesitzung tătig werden, die dem Zeitpunkt der Veroffentlichung der Meinungsăusserung und ihrer Vorlage vor dem Komitee folgt. Ersatzweise kann eine Entscheidung des Internationalen Komitees durch schriftliche Abstimmung erfolgen.

4) Es soll spezielle Subkomitees von Experten berufen und ermächtigen, sowie deren Tatigkeit und Bereiche festlegen. Diese sollen sich mit der Nomenklatur der Bakterien befassen und entsprechende Empfehlungen unterbreiten sowie uber andere Phasen der Taxonomie ihres Gebietes Bericht erstatten.

5) Es soll an jedem Internationalen Kongress die Schirmherrschaft uber die Sektion zum Thema Taxonomie abernehmen und eine soder mehrere Sitzungen dieser Sektion organisieren, bei denen Gelegenheit zur Erstattung und Erorterung von Berichten mehrerer taxonomischer Subkomitees besteht.

6). Es soll die Berichte verschiedener taxonomischer Subkomitees in Empfang nehmen und diese zur Veroffentlichung an das Herausgebergremium der Schiedskommission weiterleiten; ferner soll es der Schiedskommission alle auftretenden Fragen oder Empfehlungen zuleiten, die im Hinblick auf die Nomenklatur aufgeworfen wurden.

7) Es soll aus seiner Mitte (der Mitglieder des ICNB) die Mitglieder der Schiedskommission whhlen, wenn freie Stellen vorhanden sind und so die Mitglieder der einzelnen Klassen, deren Amtszeit ausläuft ersetzen.

8) Es soll, wenn eine Stelle frei wird, einen ständigen Sekretär nominieren.

9) Es soll Personlichkeiten, die hervorragende Dienste in der bakteriologischen Nomenklatur und Taxonomie geleistet haben, als Mitglieder des ICNB auf Lebenszeit berufen. Solche Mitglieder auf Lebenszeit sollen als zusatzliche Mitglieder und nicht als Vertreter der Mikrobiologie irgendeiner Nation angesehen werden. 
Wahl und Pflichten des Vorsitzenden und des Vize-Vorsit zenden.

Auf einer Sitzung, die auf jedem Internationalen Kongress stattfindet, soll das ICNB einen Vorsitzenden und einen Vize-Vorsitzenden wählen, die ihr Amt bis zum Abschluss des nächsten Kongresses ausuben.

A) Die Pflicht des Vorsitzenden soll sein:

(1) Bei allen Treffen des Komitees den Vorsitz zu fuhren.

(2) Mit dem Vorsitzenden der Schiedskommission, mit dem Vize-Vorsitzenden und den beiden ständigen Sekretären bei der Vorbereitung aller Tagesordnungspunkte für das Treffen des ICNB zusammenzuarbeiten.

(3) Mitglieder solcher Subkomitees zu berufen, die noch durch das Internationale Komitee zu billigen und anderweitig noch nicht vorgesehen sind.

(4) Solche andere Verpflichtungen zu ubernehmen, die vom Komitee ver langt werden.

B) Die Pflichten des Vize-Vorsitzenden des Komitees sollen sein:

(1) Bei Abwesenheit des Vorsitzenden den Vorsitz an den Treffen des Komitees zu ubernehmen.

(2) Mit dem Vorsitzenden des Komitees, dem Vorsitzenden der Schiedskommission und den beiden Ständigen Sekretären bei der Vorbereitung der Tagesordnung für Treffen der ICNB zusammen zu arbeiten.

(3) Solche anderen Pflichten zu ubernehmen, die von dem Komitee verlangt werden.

Wahl der beiden Stăndigen Sekretăre.

Zwei Stăndige Sekretäre werden von dem Komitee ge wählt und durch die Hauptversammlung des Kongresses bestătigt. Einer der Ständigen Sekretäre soll vorzugsweise die Interessen der medizinischen und veterinä $r$-medizini schen Bakteriologie vertreten und der andere die Interessen der nicht-medizinischen Bakteriologie. Sofern Vakanzen in der Stellung der Standigen Sekretäre in der Periode zwischen Kongressen der IAMS auftreten, sollten diese durch die Schiedskommission ausgefullt werden,

Solche Berufungen sind vorubergehend, wenn sie nicht vom nächsten Kongress bestätigt werden. Die Ståndigen 
Sekretăre sind zusätzliche Mitglieder mit Stimmrecht und sollen nicht in die Quote irgendeiner Nation eingeschlossen werden.

Die Pflichten der ständigen Sekretäre sollen sein:

1) Sie sollen in Zusammenarbeit mit dem Vorsitzenden des ICNB, dem Vize-Vorsitzenden des ICNB und dem Vorsitzenden der Schiedskommission die Tagesordnung für alle Treffen des Komitees und der Schiedskommission vorbereiten.

2) Sie sollen ex officio als stimmberechtigte Mitglieder und als gemeinsame Sekretâre der Schiedskommis sion tätig sein.

3) Sie sollen Nominierungen aus dem Kreise der verschiedenen nationalen mikrobiologischen Gesellschaften für die Mitgliedschaft sicherstellen und sollen, wenn solche Nominierungen im Einklang mit den Vorschriften dieses. Nomenklaturkodex stehen, den so Nominierten eine Bestätigung ihrer temporären Mitgliedschaft ubergeben. Sie sollen weiter eine Nominierungsliste fur die Mitgliedschaft zur Vorlage an das Komitee beim ersten Treffen eines jeden Internationalen Kongresses vorbereiten.

4) Sie sollen von der Schiedskommission solche Empfehlung an das Komitee weiterleiten, bei dénen das Komitee tătig werden musste. In dem Intervall zwischen Internationalen Kongressen sollen sie solche Empfehlungen vervielfältigen und an alle Komitee-Miglieder weiterleiten. Wenn die KomiteeMitglieder durch Rundschreiben verständigt sind, sollen sie Kommentare und Vorschläge einholen und die erhaltenen Informationen ubersichtlich zusammenstellen. Falls die Komitee-Mitglieder zur Abstimmung uber irgendwelche Vorschläge aufgefordert werden, sollen sie das Abstimmungsergebnis ubersichtlich zusammenstellen und bekanntgeben; daruber hinaus sollen sie das Ergebnis dem Vorsitzenden des Komitees und dem Vorsitzenden der Schiedskommission verbindlich bestätigen.

5) Sie sollen gemeinsam mit dem Vorsitzenden der Schiedskommission und dem Schriftleitungs-Sekretär als Mitglieder des Herausgebergremiums tätig sein, um alle Meinungsăusserungen der Schiedskommission zu bearbeiten und fur die endgultige Veroffentlichung vorzubereiten. Das Gleiche gilt fur den Internationalen Kodex fur die Nomenklatur 
der Bakterien und seine Ergänzungen sowie fur $r$ alle Veroffentlichungen, die im Namen des Komitees oder der Schiedskommission erscheinen oder von dieser gefordert werden.

6) Sie sollen bei den Sitzungen des Komitees und der Schiedskommission Protokoll fuhren und dieses zur Veroffentlichung in den Verhandlungsbericht des betreffenden Internationalen Kongresses und im Internationa L Journal of Systematic Bacteriology einreichen.

7) Sie sollen der Hauptversammlung des Kongresses uber alle Schritte der Schiedskommission und des ICNB, die einer Billigung bedurfen, Bericht erstatten. Diesen beigeschlossen sind Namen- und Adressenlisten der Mitglieder.

8) Einer der beiden ständigen Sekretăre soll Mitglied eines jeden, vom ICNB ermächtigten oder berufenen taxonomischen Subkomitees sein, um eine Verbindung zwischen den Subkomitees, der ICNB und der Schiedskommission aufrechtzuerhalten. Er sroll vom Sekretär des Subkomitees Berichte und Empfehlungen entgegennehmen und diese dem ICNB und der Schiedskommission weiterleiten.

9) Sie sollen gemeinsam mit den Vorsitzenden des ICNB die Bildung neuer Subkomitees uber die Nomenklatur und Klassifizierung bestimmter Gruppen von Mikroorganismen offiziell in die Wege leiten. Solche Subkomitees sollen nur einen vorläufigen Status haben, bis sie durch entsprechende Massnahmen des ICNB in aller Form ermächtigt werden konnen.

Bestimmungen und Pflichten eines Schriftleitungs-Sekretärs.

Ein Schriftleitungs-Sekretär wird von der ICNB gewăhlt und durch die Hauptversammlung der IAMS bestätigt. Eine Vakanz imAmt des Schriftleitungs-Sekretärs, die in der Zeit zwischen zwei Kongressen der IAMS auftreten kann, s'oll durch die Schiedskommission besetzt werden. Eine diesbezügliche Besetzung soll temporär sein, bis sie durch das Internationale Komitee bestätigt wird. Der Schrift leitungs-Sekretâr ist ein zusâtzliches Mitglied des ICNB und soll nicht in der Quote irgendeiner Nation gezâhlt werden. Der Schriftleitungs-Sekretăr ubt seine Tátigkeit als Schriftfuhrer der Schiedskommission und als Mitglied 
des Herausgeber-Gremiums der Schiedskommission aus.

Organisation und Aufgabe der taxonomischen Subkomitees.

Vorschläge fur die Bildung taxonomischer Subkomitees konnen von Einzelpersonen oder von Gruppen an einen der Ständigen Sekretäre eingereicht werden. Solch einem Ersuchen sollte eine Aufstellung uber die vorgeschlagenen Aufgaben des Subkomitees und eine Liste der vorgeschlagenen Mitglieder beigefugt werden. Taxonomische Subkomitees von Experten, die vom ICNB ermächtigt und berufen sind, sollen unter folgenden Regeln arbeiten:

1) Mitglieder eines Subkomitees. Der Vorsitzende des Internationalen Komitees wählt gemeinsam mit den beiden Ständigen Sekretären des Komitees Mitglieder des neuen taxonomischen Subkomitees aus, und zwar aus den vorgeschlagenen und anderen Namen. Sie berufen einen zeitweiligen Vorsitzenden und Sekretăr, die mit den Mitgliedern des taxonomischen Subkomitees solange tátig sind, bis das Subkomitee seinen Vorsitzenden und Sekretär wählt und seinen Mitgliederbestand revidieren kann.

2) Der Vorsitzende und Sekretär jedes taxonomischen Subkomitees soll von den Mitgliedern des Subkomitees gewählt werden und das Amt für die Zeitspanne von Beginn bis zum Ende zweier aufeinander folgender Kongresse innehaben. Sie sollen wiederwählbar sein.

3) Einer der beiden Ständigen Sekretäre soll als nicht stimmberechtigtes Mitglied eines jeden Subkomitees bestimmt werden und die Verbindung zwischen dem Subkomitee, dem ICNB und der Schiedskommission aufrechterhalten.

4) Jedes taxonomische Subkomitee soll bei jedem Inter nationalen Mikrobiologie-Kongress zusammentreffen und regelmässig seinen Mitgliederstand uberprüfen und ergänzen. Die Namen der Mitglieder, die auf eigenen Wunsch ausgeschieden sind oder ihr Interesse an der Arbeit des taxonomischen Subkomitees aufgegeben haben, sollen aus der Mitgliederliste gestrichen werden.

5) Der Vorsitzende und Sekretär jedes taxonomischen Subkomitees sind fur Herstellung und Erstattung eines $B$ erichtes verantwortlich, der uber den 
Ständigen Verbindungssekretär an das ICNB gelangt. Dieser Bericht wird nach seiner Entgegennahme durch das ICNB im International Journal of Systema tic Bacteriology veroffentlicht. Der Bericht soll einen Überblick uber die Tätigkeit während der Zeitspanne, die dem Treffen des vorhergehenden Internationalen Kongress folgt, sowie eine Kopie des Sitzungsprotokolls vom Treffen während des laufenden Internationalen Kongresses enthalten. Die berichtigte Mitgliederliste des Subkomitees soll unmittelbar nach jedem Mikrobiologischen Kongress an den Verbindungssekretär eingereicht werden.

6) Ein taxonomisches Subkomitee kann Mitarbeiter auffordern, spezielle Fragen zu untersuchen. Solche Mitarbeiter brauchen selbst nicht Mitglieder des Subkomitees zu sein.

7) Die Hauptfunktionen eines taxonomischen Subkomitees sind zweifach:

L. Sie sollen For schungen aber die Beziehungen der Organismen, diverse Einheiten und Untergruppen des zu untersuchenden Taxons anstellen und dabei bessere Klassifizierungen unter dem Gesichtswinkel der praktischen Identifizierung zu entwickeln suchen, ohne jedoch die Bedeutung von Beiträgen zu ubersehen, die ein besseres Verständnis der phylogenetischen Zusammenhänge bewirken und

2. sie sollen Ratschläge und Empfehlungen bezuglich der Nomenklatur erteilen.

Die Subkomitees werden ermutigt, alle nur denkbaren technischen Verfahren der verschiedenen Zweige der Wissenschaft heranzuziehen, die bei der Erkennung von Merkmalen zur Untersuchung der verschiedenen Bakterien nutzlich sind. Gebotene Änderungen der Regeln und Em:pfehlungen'im bakteriologis chen Kodex sollten beachtet und wunschenswerte Verbesserungs vorschläge sollten der Schiedskommission unterbreitet werden. *)

*) Obwohl eine Klassifizierung nicht durch Anordnung geschaffen oder rechtswirksam gemacht werden kann, so kann doch in den meisten Bereichen durch Meinungsaus gleich (Konsensus) eine vernunftigerweise hinreichend stabilisierte Taxonomie entwickelt werden. 
Die Abfassung von Monographien uber taxonomische Gruppen ist erwänscht. Besonders bedeutsam ist die Anerkennung von Typ-Spezies von Gattungen und der TypStämme von Arten und subspezifischen Taxa, desgleichen die Festlegung von Neotyp-Stämmen von Arten und subspezifischen Taxa, sowie die Hinterlegung dieser Stämme in Kultursammlungen, von denen sie zur Verteilung erhâlt lich sind. Nicht weniger wichtig ist die formelle Ausar. beitung einer besseren nomenklatorischen $B$ ehandlung und Taxonomie der infrasubspezifischen Formen.

8) Mitglieder, die am Treffen der Subkomitees nicht teilnehmen konnen, durfen Vertreter bestimmen, die an ihrer Stelle handeln. Ein Vertreter soll von dem Mitglied mit einer schriftlichen Ermächtigung versehen werden, damit er im Namen des Mitglieds mit abstimmen kann.

\section{Vorschrift 5.}

\section{Bestellung einer Schiedskommission.}

Eine Schiedskommission wird rechtmässig bestellt. Sie soll aus 16 Mitgliedern bestehen; 12 davon werden von den Mitgliedern des ICNB aus deren Mitte gewăhlt, ferner dem Vorsitzenden dieses Komitees, den beiden Ständigen Sekretären und dem Sekretär der Schriftleitung. Der Sekretâr der Schriftleitung des ICNB ist gleichfalls Sekretär der Schriftleitung der Schiedskommission. Die Kommissionsmitglieder werden in der Weise gewählt, dass sie in drei Klassen aus je 4 Kommissionsmitgliedern dienen und jeweils eine Klasse am Ende eines jeden Internationalen Kongresses der IAMS ausscheidet.

Mitglieder der ausscheidenden Klasse sind wiederwăhlbar.

Im Falle des Rucktritts oder Todes eines Kommissions mitgliedes zwischen den Kongressen kann der frei werdende Platz durch Briefwahl der Mitglieder des Internationalen Komitees besetzt werden. Wenn ein Kommissionsmitglied an den Treffen der Schiedskommission nicht teilnehmen kann, wird ein Vertreter mit allen Rechten eines Kommis sionsmitgliedes, aber ohne Wahlrecht bei der Vor stands wahl, im Einklang mit den folgenden Vorschriften bestellt:

a) Das Kommissionsmitglied selbst soll das Recht haben, einen Vertreter zu benennen.

b) Wenn von dem Kommissionsmitglied keine Nominie rung erfolgt, wird die Schiedskommission einen 
Vertreter aus dem Kreis der Komiteemitglieder wăhlen, die am Kongress teilnehmen.

Alle Nominierungen mussen schriftlich eingereicht werden und dem Vorsitzenden der Schiedskommission vor dem ersten Treffen der Kommission vorliegen. Alle Nominierungen für Vertreter sollen bei der ersten Kommissions sitzung vorgelegt werden. Die durch Abstimmung der Kommission gewählten Kandidaten werden als Vertreter dienen.

Durch die Wahl der Schiedskommission soll eines der Kommissionsmitglieder als Vorsitzender und eines als Vize-Vorsitzender bestellt werden. Der Vorsitzende und der Vize-Vorsitzende sollen so lange im Amt bleiben, wie ihre volle Amtszeit als Kommissionsmitglied wăhrt.

\section{Pflichten des Vorsitzenden der Schiedskommission.}

1) Er soll den Vorsitz bei den Treffen der Schiedskommission fuhren.

2) Er soll in Zusammenarbeit mit den Ständigen Sekretâren des Komitees das Verhandlungsprogramm der Schieds kommission vorbereiten.

3) Er soll die Berufung solcher Komitees vornehmen, zu deren Bildung die Schiedskommission Ermächtigung erteilt, sofern anderweitig keine Vorkehrungen dafur getroffen sind.

4) Er soll den Vorsitz in der Schriftleitung gemeinsam mit den beiden Ständigen Sekretären führen. Diese Schriftleitung trägt die Verantwortung für die Bearbeitung und Zusammenstellung zur Veroffentlichung der Meinungsăusserungen, die von der Schiedskommission abgegeben werden, des Internationalen Kodex fur die Nomenklatur der Bakterien mit Ergänzungen sowie für alle anderen Veroffentlichungen, deren Herausgabe durch die Schiedskommission oder das ICNB erfolgt oder gefordert wird.

5) Er soll in Zusammenarbeit mit den Ständigen Sekretären und dem Sekretăr der Schriftleitung vorläufige Formulierungen von Meinungsâusserungen und Vorschläge als Diskussionsgrundlage sowie für eine Abstimmung durch die Mitglieder der Schiedskommission ausarbeiten und soll die Sammlung, Sichtung und Zusammenstellung der Ergebnisse vornehmen. Ferner soll er in Zusammenarbeit mit den Ständigen Sekretären und dem Schriftleitungssekretär Ersuchen 
oder Vorschläge zur Ergänzung des Internationalen Kodex fur die Nomenklatur der Bakterien in geeignete Form für die Bearbeitung bringen, solche Ersuchen oder Formulierungen an die Kommissionsmitglieder in Umlauf geben, zur Abstimmung aufrufen, die Ergebnisse zusammenstellen und dem ICNB geeignete Empfehlungen vorlegen.

6) Er soll uber alle Ersuchen um Meinungsäusserungen und um Beistand in Nomenklaturfragen, die der Kommission vorgetragen werden, Buch fuhren und die Meinungs-

ausserungen der Schiedskommission schnellstens formulieren und veroffentlichen.

7) Er soll auf dem Wege uber die Ständigen Sekretäre die Meinungsäusserungen nach ihrer Abgabe durch die Schiedskommission sowie alle Empfehlungen und Massnahmen der Schiedskommission, die einer Bearbeitung oder Zustimmung des ICNB bedürfen, an das ICNB weiterleiten.

8) Er soll die Schiedskommission bei solchen Internationalen Komitees, Gremien oder Kommissionen vertreten, die zur Erorterung der Zusammenarbeit im biologischen Bereich bei der Losung gemeinsamer Nomenklaturund Taxonomiefragen ins Leben gerufen werden; vor allem aber soll er mit anderen ahnlichen Kommissionen des Exekutiv-Komitees zusammenarbeiten, die zur $B$ ehandlung von Nomenklaturproblemen in der Botanik und Zoologie organisiert werden.

9) Schliesstich soll er jene zusatzlichen Pflichten ubernehmen, die von Zeit zu Zeit von der Schiedskommission gewanscht werden.

\section{Aufgaben der Schiedskommission.}

Die Schiedskommission hat folgende Aufgaben:

1) Sie soll regelmässig Sitzungen abhalten, die zur Verhandlung aller jener Angelegenheiten notwendig sind, welche ihr zur Zeit der Sitzungen eines jeden Kongresses der IAMS vorgelegt werden sollen.

2) Sie soll alle Ersuchen um Meinungsäusserungen hinsichtlichı der Auslegung der Grundsätze, Regeln, Empfehlungen und Vorschriften des Internationalen Kodex fur die Nomenklatur der Bakterien uberdenken, wenn deren Anwendung zweifelhaft ist. Ein Ersuchen um eine Meinungsäusserung sollte von einer erschøpfend dokumentierten Darlegung aller bedeutsamen Fakten 
begleitet sein. Wenn ein Ersuchen nicht durch hinreichende Beweise gestützt ist, soll es dem Autor zur Uberarbeitung zurückgegeben werden. Wenn eine Meinungsäusserung angegriffen wird, soll der Grund der Ablehnung dargelegt und durch eine dokumentarisch belegte Feststellung aller bedeutsamen Fakten gestutzt werden.

In geeigneten Fallen soll eine Meinungsăusserung erstellt und, wenn sie von 8 oder mehr Kommissions. mitgliedern gebilligt ist, abgegeben und veroffentlicht werden, wodurch sie als Wegweiser allen Bakteriologen zugänglich wird. Alle Meinungsäusserungen werden der ICNB mitgeteilt und sind endgültig, wenn sie nicht durch Mehrheitsabstimmungsbeschluss rllckgängig gemacht werden.

3) Sie soll jeden Vorschlag fur eine Verbesserung des Inter nationalen Kodex fur die Nomenklatur der Bakterien uberprufen und Empfehlungen fur solche Verbesserungen formulieren. Wenn die Zustimmung von 8 oder mehr Kommissionsmitgliedern vorliegt, sollen sie an die Mitglieder der ICNB weitergeleitet werden. Ein Verbesserungsvorschlag soll als vorläufig gebilligt angesehen werden, wenn er von $700 / 0$ der abstimmenden Mitglieder angenommen worden ist. Er soll zur endgültigen Billigung der nächstfolgender. Hauptver sammlung eines Internationalen Kongresses vorgelegt werden.

4) Sie soll eine Liste der Namen der Taxa aufstellen, die auf der Grundlage von Meinungsäusserungen im Hinblick auf den Status solcher Namen erhalten werden sollen (nomina conservanda).

5) Sie soll Listen von Typen vorbereiten und veroffentlichen, die durch Abgabe von Meinungsäusserung durch die Schiedskommission festgelegt worden sind.

6) Sie soll Namenslisten von Bakteriengattungen vorbereiten und veroffentlichen, die gültig veroffentlicht sind, und sofern ratsam - Listen von Gattung snamen anderer Gruppen, an denen Mikrobiologen interessiert sind. Solche Listen wurden dazu bestimmt sein, Autoren, die neue Namen und Kombinationen veroffentlichen, zu helfen, den Vorschlag illegitimer späterer Homonyme zu vermeiden.

7) Sie soll eine Liste von Veroffentlichungen im Bereich aller Beschreibungen vorbereiten und veroffentlichen, in denen vorgeschlagene Namen aufgefthrt sind, die als nicht gultig veruffentlicht angesehen werden und keinen bakteriologischen Nomenklaturstatus haben sollen. 
8) Sie soll dem ICNB am ersten Treffen eines jeden Internationalen Kongresses die Namen aller Kommissions mitglieder mitteilen, deren Amtsperiode am Ende des Kongresses auslâuft, ferner eine Liste aller anderen frei gewordenen Stellen im Mitgliederbestand der Kommission, die im Wahtverfahren durch das Inter nationale Komitee besetzt werden sollen.

9) Sie soll durch ihren Vorsitzenden und in Zusammenarbeit mit den ständigen Sekretären mit anderen Kommis sionen oder Korperschaften zusammenarbeiten, die zur B earbeitung von Nomenklaturproblemen von den Internationalen Botanischen oder Zoologischen Kongressen berufen werden.

10) Sie soll - nach Billigung durch das Internationale Komitee - solche Treuhandschaften übernehmen bzw. in solche Vereinbarungen eintreten, wie sie zur Rechnungsprüfung, und Verwaltung von Fonds ratsam erscheinen, die zur Bezahtung notwendiger Betriebsunkosten der Schiedskommission oder des ICNB bestimmt sind oder die von Stipendien, Spenden, Tantiemen aus Verkaufs erlosen von Veroffentlichungen oder aus anderen Quellen stammen.

11) Sie soll bei der zuständigen internationalen Korperschaft der Vereinten Nationen, bei anderen Organisationen oder bei Stiftungen Stipendien zur Begleichung der für die Arbeit der Schriftleitung und des Internationalen Komitees notwendigen Ausgaben beantragen.

12) Sie soll solche Veroffentlichungen, Bulletins oder Zeitschriften fordern oder selbst herausgeben, die notwendig erscheinen, um in angemessener Weise Ersuchen um Meinungsäusserungen der Schiedskommission und die Erorterung derselben darzulegen und die einzelnen Schritte vor Beginn der Untersuchungen bis zur abschliessenden Meinungsäusserung, Aufhebung einer Regel oder der Zuordnung zu den Listen von Nomina conservanda oder Nomina rejicienda bekannt zu machen.

13) Sie soll solche Veroffentlichungen, Bulletins oder Zeitschriften: fordern oder selbst herausgeben, die als ratsam fur den Fortschritt der systematischen Bakteriologie einschliesslich des Internationalen Kodex für die Nomenklatur der Bakterien erachtet werden. Unter der Patenschaft und Leitung der Schiedskommission wird die unmittelbare Aufsicht uber Veroffentlichungen einer Publikation dem Herausgebergremium ubertragen. 


\section{Organisation und Aufgabe des Publikationsgremiums}

a) Ein Publikationsgremium der Schiedskommission wird bestellt.

L. Die Mitgliedschaft des Publikationsgremiums soll bestehen aus dem Vorsitzenden der Schiedskommission, der Vorsitzender des Gremiums sein soll, dem Herausgeber oder den Herausgebern von Veroffentlichungen, die mit Ermächtigung der Schiedskommission . erscheinen, der Ständigen Sekretäre und dem Sekretär der Schriftleitung.

b) Aufgeben des Publikationsgremiums:

Das Publikationsgremium soll die Arbeit der Schriftleitungen koordinieren, die durch Akt der Schiedskommission zur Tătigkeit ermächtigt werden können, Bis zu dem Zeitpunkt, an dem die Ermächtigungen an Schriftleitungen erteilt sind, die fur das International Journal of Systematic Bacteriology, den Internationalen Kodex fúr die Nomenklatur der Bakterien oder andere geforderte Veroffentlichungen ausgewählt sind, wird das Publikationsgremium als Schriftleitung fur alle Veroffentlichungen fungieren, die nicht bereits eine nahher bezeichnete Schriftleitung haben. Das Publikationsgremium soll der Schiedskommission entsprechende Empfehlungen hinsichtlich der Grüdung von Schrift leitungen fur die verschiedenen Veroffentlichungen unterbreiten, damit diese zweckentsprechend handeln konnen. 